\title{
INVESTIGACIÓN
}

Recibido: 27/05/2016 ----- Aceptado: 14/11/2016 ----- Publicado: 15/03/2017

\section{RECONCEPTUALIZACION DE LA EDUCACIÓN EN LA ERA DIGITAL: EDUCOMUNICACIÓN, REDES DE APRENDIZAJE Y CEREBRO. FACTORES CLAVES EN LOS ACTUALES ESCENARIOS DE CONSTRUCCIÓN DE CONOCIMIENTO}

Yeldy Milena Rodríguez García1: Escuela Superior de Administración Pública ESAP. Colombia

yeldrodr@esap.edu.co

\section{RESUMEN}

El concepto de educación requiere una reconceptualización, por parte de docentes y estudiantes, de cara a los desafíos de la revolución digital en términos comunicativos, que impactan directamente en los procesos educativos. Alta concordancia entre la conceptualización y la realidad educativa actual, reduce las posibilidades de sufrir frustración, disminuir la motivación, por ende el aprendizaje y no cumplir las expectativas.

El artículo presenta resultados parciales de tesis doctoral denominada: "Reconceptualización de la educación en la era digital. Educomunicación, redes de aprendizaje y cerebro: una visión desde la neurociencia cognitiva a los procesos de construcción de conocimiento en entornos digitales" realizada en el contexto universitario colombiano (años 2012 a 2016). El fundamento teórico es la filosofía y la práctica educomunicativa y el enfoque Conectivista. El objeto principal fue analizar los conceptos de educación digital, las practicas educomunicativas, de redes de aprendizaje y perfiles cognitivos de muestra de 3643 estudiantes y 300 docentes de diferentes programas a nivel de pregrado, ambos neófitos en educación virtual y evidenciar si existía alguna relación con los procesos de construcción de conocimiento.

Los resultados sugieren, que los preconceptos sobre las prácticas educativas digitales de docentes y estudiantes, influyen de forma significativa en los procesos de aprendizaje, comunicación, conductas y convivencia en estos entornos, pero también las evidencias cuantitativas y cualitativas soportan que estos preconceptos cambian en sentido positivo, cuando se experimentan didácticas acordes a la edad, al estilo cognitivo y con un enfoque educomunicativo y relacional. Las conclusiones presentan aspectos por mejorar y prospectiva.

\footnotetext{
${ }^{1}$ Yeldy Milena Rodríguez García: Coordinadora del equipo de Educación y Entornos Digitales de la Subdirección Académica de la Escuela Superior de Administración Publica ESAP. Docente e investigadora en neurociencia cognitiva y construcción del conocimiento en entornos digitales.

correo: yeldrodr@esap.edu.co
} 
Rodríguez García, Y. M. Reconceptualizacion de la educación en la era digital: educomunicacion, redes de aprendizaje y cerebro. Factores claves en los actuales escenarios de construcción de conocimiento

PALABRAS CLAVE: concepto educación - cerebro - educomunicación - era digital -redes de aprendizaje - construcción de conocimiento - reconceptualización de la educación

\title{
RECONCEPTUALIZATION OF EDUCATION IN THE DIGITAL ERA: EDUCOMINICATION, LEARNING NETWORKS AND BRAIN. KEY FACTORS IN THE CURRENT SCENARIOS OF CONSTRUCTION OF KNOWLEDGE
}

\begin{abstract}
The concept of education requires a re-conceptualization by teachers and students of the challenges of the digital revolution in communicative terms, which have a direct impact on educational processes. A greater degree of agreement between the conceptualization and the current educational reality reduces the chances of frustration, decrease motivation, thus learning and not meeting the expectations of teachers and students.

The article presents partial investigative results of the doctoral thesis denominated: "Reconceptualization of education in the digital era. Educommunication, learning networks and brain: a view from cognitive neuroscience to the processes of knowledge construction in digital environments" carried out in the Colombian university educational context between 2012 and 2016. The theoretical foundation of this research is the philosophy and the practice educomunicative and the conectivist approach. This work aimed to analyze the concepts of digital education, educational practices, learning networks and cognitive profiles of a sample of 3643 students and 300 teachers of different programs at undergraduate level, both neophytes in virtual education and evidence if there was some relation to the processes of knowledge construction.

The results suggest that preconceptions about the digital educational practices of teachers and students influence significantly the processes of learning, communication, behaviors and coexistence in these environments, but also the quantitative and qualitative evidences support that these preconceptions can change in positive sense, when experiencing pedagogical didactics according to age, cognitive style and with an educomunicative and relational approach. In the conclusions the aspects to improve and the prospective one are presented.
\end{abstract}

KEY WORDS: Education - brain - edu communication - digital age - learning networks - knowledge construction - reconceptualization of education

\section{RECONCEITUAÇÃO DA EDUCAÇÃO NA ERA DIGITAL: EDUCOMUNICAÇÃO, REDES DE APRENDIZAGEM E CÉREBROS. FATORES CHAVES NOS ATUAIS CENÁRIOS DA CONSTRUÇÃO DO CONHECIMENTO}

\author{
RESUMO \\ O conceito da educação requer uma reconceituação, por parte dos docentes e \\ estudantes, diante dos desafios da revolução digital em termos comunicativos, que
}


Rodríguez García, Y. M. Reconceptualizacion de la educación en la era digital: educomunicacion, redes de aprendizaje y cerebro. Factores claves en los actuales escenarios de construcción de conocimiento

impactam diretamente nos processos educativos. Alta concordância entre conceituação e a realidade educativa atual, reduz as possibilidades de sofrer frustrações, diminuir a motivação, não cumprir as expectativas e, portanto melhorar a aprendizagem.

O artigo apresenta resultados parciais de teses doutorais denominada: "Reconceituação da educação na era digital. Educomunicação, redes de aprendizagem e cérebro: uma visão desde o ponto de vista da neurociência cognitiva aos processos de construção do conhecimento em entorno digitais" realizada num contexto universitário colombiano (2012 a 2016). O fundamento teórico é a filosofia, a prática educomunicativa e o enfoque Conectivista. $\mathrm{O}$ objetivo principal foi analisar os conceitos da educação digital, as práticas educomunicativas, de redes de aprendizagem e os perfis cognitivos de amostras de 3.643 estudantes e 300 docentes de diferentes programas ambos neófitos em educação virtual e evidenciar se existia alguma relação com os processos de construção do conhecimento.

Os resultados sugerem, que os preconceitos sobre as práticas educativas digitais de docentes e estudantes, influem de forma significativa nos processos de aprendizagem, comunicação, condutas e convivência nesses entorno, mas também as evidencias quantitativas e qualitativas mantém que estes preconceitos mudam no sentido positivo, quando experimentam didáticas de acordo com a idade, o estilo cognitivo e com um enfoque educomunicativo e relacional. As conclusões apresentam aspectos para melhorar e prospectiva.

PALAVRAS CHAVE: Conceito educação - Cérebro - Educomunicação - Era digital Redes de aprendizagem - Construção do Conhecimento - Reconceituação da Educação.

\section{Cómo citar el artículo}

Rodríguez García, Y. M. (2017). Reconceptualizacion de la educación en la era digital: educomunicacion, redes de aprendizaje y cerebro. Factores claves en los actuales escenarios de construcción de conocimiento [Reconceptualization of education in the digital era: educommunication, learning networks and brain: key factors in the current scenarios of construction of knowledge] Revista de Comunicación de la SEECI, no 42, 85-118 https://doi.org/10.15198/seeci.2017.42.85-118 Recuperado de http://www.seeci.net/revista/index.php/seeci/article/view/454

\section{INTRODUCCIÓN}

La formación de conceptos es un componente esencial que posibilita o retrasa procesos de aprendizaje, creativos y de desarrollo del conocimiento; este proceso siempre obedece a aprendizajes previos de cada individuo, que lo potencian o limitan, y que se reconstruyen constantemente basándose en la interacción de factores internos y externos; por esto el conocimiento no es uno, es tantos como reconstrucciones mentales individuales existan. La dinámica de los procesos de construcción de conocimiento, no se anclan a la formalidad de escenarios educativos y obedecen a la propiedad cerebral Ilamada "Plasticidad cerebral" que permite adaptarnos frente a las cambiantes condiciones ambientales, cerebros más jóvenes, 
Rodríguez García, Y. M. Reconceptualizacion de la educación en la era digital: educomunicacion, redes de aprendizaje y cerebro. Factores claves en los actuales escenarios de construcción de conocimiento

se adaptan a una tasa más rápida que cerebros de personas adultas. (Diego Redolar Ripoll, 2014).

La era digital progresivamente demanda, estar permeables a prácticas educomunicativas que involucran la formación de redes de aprendizaje, de colaboración y comunidades de práctica significativas, estas mediaciones causan cambios conductuales y cognitivos cerebrales que fortalecen la construcción de conocimientos necesarios en la era digital, como: aprender a conocer, sentir, hacer, convivir y ser (López, A 2009). De forma tal que la experiencia puede modificar los preconceptos y posibilitar la apertura mental a las dinámicas propias de la sociedad red.

Ante los cambios y retos que nos propone el entorno comunicativo, facilitado por las tecnologías relacionales, este estudio pretende indagar el punto de partida 0 preconcepto de estudiantes y docentes sobre la educación virtual, y su incidencia en los procesos de construcción de conocimiento, así como también determinar la adaptabilidad de los grupos estudiados para deconstruir y construir conceptos nuevos sobre los entornos digitales a partir de la experiencia, que posibiliten conductas, habilidades sociales, destrezas intelectuales y psicomotoras que faciliten el trabajo en equipo, así como la integración de saberes.

Es innegable que la cultura humana cambio y seguirá cambiando y el cerebro también continuo evolucionando; temas de atención y percepción, parcialización de funciones, construir identidad, comunicarse es diferente. La tecnología en red posibilita que se esté modificando nuestra capacidad de procesamiento y atención, el uso y la gestión que hacemos de la información, la forma de conceptualizar las redes, el cerebro en red está más activo, conectado, motivado, puede funcionar de forma fragmentada, reacciona más rápido. Si los docentes no prestamos atención a tantos retos, no posibilitaremos una educación significativa y pertinente. Concomitante con lo anterior, hoy se propone por investigadores como Carmen Marta Lazo y José Antonio Gabelas Barroso, de la Universidad de Zaragoza, el desarrollo de habilidades para la vida, sociales, emocionales comunicativas y cognitivas; así como también el desarrollo de competencias tecnológicas, cooperativas, interactivas, de identidad, de compromiso ciudadano y del reuso o remix, de la información disponible. Los autores proponen un sistema educativo que tenga en cuenta el cerebro y que integre las competencias mediáticas pasando de la dimensión instrumental y cognitiva a la actitudinal y axiológica para una cultura más humanizada. (Carmen Marta Lazo y José Antonio Gabelas Barroso, 2016).

La reconceptualización de la educación también debe darse dada la ocurrencia de fenómenos en red como: el trabajo colaborativo que ofrece también la posibilidad de coocrear, término que se discute en las llamadas comunidades tecnosociales, tal como menciona Lucia Camarero, investigadora de la UNED: "Los seres humanos siempre hemos formado redes sociales. Son éstas las que nos han ayudado a evolucionar como sociedad y las que han dado lugar a la creación y desarrollo de comunidades". L Camarero-Cano (2015), los conceptos sobre formación de 
Rodríguez García, Y. M. Reconceptualizacion de la educación en la era digital: educomunicacion, redes de aprendizaje y cerebro. Factores claves en los actuales escenarios de construcción de conocimiento

comunidades y la socialización como acto natural y necesario para el cerebro, debe tenerse en cuenta en los nuevos conceptos educativos, está demostrado que los procesos sociales en red aumentan la producción de dopamina un neurotransmisor que se produce en estados de placer y que abre los canales cognitivos, es así como se explica también las adicciones a la tecnología y la dependencia emocional de las redes sociales, aspectos que no se contemplaban en los conceptos educativos clásicos (Camarero, L. 2015).

El contexto: Colombia es el cuarto país en extensión territorial de América del Sur, con 47 millones de habitantes (la tercera población en América Latina), es uno de los países más diversos en su población como en recursos naturales y uno de los más multiculturales, en regiones y etnias del mundo. En esta latitud, la educación significativa, es el principal medio para superar la marginación social y económica, salir del subdesarrollo y posibilitar la participación social. A pesar de los avances en disponibilidad, accesibilidad y adaptabilidad en términos educativos, Colombia pasa por un momento de transición y articulación hacia las metas mundiales de desarrollo en la era digital, que nos exige repensar nuestras prácticas educativas, comunicativas, aspectos cognitivos y dinámicas de aprendizaje propias de nuestra idiosincrasia y códigos culturales, morales y legales; lo que se constituye en un reto y oportunidad para las instituciones educativas, en atención a las necesidades de los estudiantes, los docentes y la sociedad en la que se desenvuelven.

¿Por qué la necesidad de reconceptualizar la educación, en la era digital, por parte de los docentes? Actualmente el Sistema Nacional de Instituciones de Educación Superior (SNIES), reporta que existen 69 maestrías en Educación en Colombia, 60 se ofrecen en modalidad presencial (entre estas se destacan 3 clasificadas de alta calidad) y 6 se ofrecen en modalidad virtual y 3 en modalidad a distancia. EL SNIES también reporta que en Colombia hay 7 programas de doctorado en educación, todos ofrecidos en modalidad presencial, de los cuales solo 1 es reconocido de alta calidad (impartido por la Universidad de Antioquia). Las anteriores cifras nos dan un indicativo de la modalidad preponderante en que los docentes se educan que es presencial y de la existencia de un número importante de programas de maestría en educación sin acreditación de alta calidad y tan solo un programa de doctorado acreditado de alta calidad. (Sistema Nacional de Información de la Educación superior, SNIES, 2016)

Las anteriores evidencias nos muestra que los docentes en Colombia, son formados en su mayoría en programas presenciales, por lo que sus competencias digitales y el consecuente uso de medios y mediaciones acordes a la cultura digital es limitada. También se puede analizar que hay un interés por parte de las Universidades en ofrecer programas de maestría para los docentes pero que sólo $4 \%$ de los programas que se ofrecen es de alta calidad, subsecuentemente la poca existencia de doctorados en educación y sólo uno con alta calidad, refleja grandes vacíos en investigación en los fenómenos de educación. Lo que da como resultado un sistema educativo para docentes, anquilosado en el tiempo que no se articula a las necesidades sociales actuales y que deja muy a discreción del docente el aprovechamiento de los medios y mediaciones para la educación de la era digital. 
Rodríguez García, Y. M. Reconceptualizacion de la educación en la era digital: educomunicacion, redes de aprendizaje y cerebro. Factores claves en los actuales escenarios de construcción de conocimiento

A pesar de los esfuerzos del Ministerio de Educación Nacional (MEN) y el Ministerio de Tecnologías de la Información y la Comunicación (MIN TIC) en la generación de políticas para el fortalecimiento de la educación y del crecimiento en acceso a la tecnología y conectividad. (Ministerio de Tecnologías de la Información y la Comunicación, 2016; Ministerio de Educación Nacional de Colombia 2010 y 2014). Los avances en educación para docentes han sido lerdos y tenemos grandes vacíos en formación para ejercer la docencia en el contexto global actual, vacíos en términos de investigación, de formación en competencias digitales, de reconocimiento a la profesión y de remuneración para los docentes; esta falta de articulación entre las políticas y las prácticas académicas para formar docentes trae como consecuencia que el problema mayor en términos de educación, que se relaciona con los malos resultados en las pruebas internacionales y nacionales y en general de desarrollo, no radica en la tecnología, ni en el acceso a ella, sino en la debilidad del sistema educativo que forma a los docentes para la era global de la información, en términos de gestión de la información, en procesos de construcción crítica del conocimiento, en temas éticos, que llevan a que continúen fenómenos sociales como la corrupción que a su vez favorece el subdesarrollo, como un círculo recurrente.

En el contexto universitario, docentes, en su mayoría, están de acuerdo con las tecnologías de la información y la comunicación, pero sus prácticas distan de un entendimiento profundo sobre ir más allá de la herramienta, sobre los cambios de las propuestas pedagógicas propias de la era digital, que plantean una didáctica con conceptos abiertos de conformación de redes cognitivas, a través del uso de los medios no convencionales de enseñanza, buscando aprovechar la creatividad. Surge la necesidad de que estudiantes y docentes reconceptualicen la educación en la era global de la información, en los que el uso y entendimiento de lo que posibilitan las tecnologías, como humanidad, despejan el camino que facilita el ingreso a una real sociedad red, de la información y posiblemente del conocimiento.

La necesidad de humanizar la educación es un tema clave en un país como Colombia, donde el tema ético, el de vivir los valores, han sido tan descuidados que prima la corrupción, la violencia y la guerra como modelo de proceder normalizado. La Universidad Colombiana necesita repensar la educación por parte de los estudiantes y de los docentes, en el contexto cultural que hoy se presenta, y trascender los medios para llegar a las mediaciones donde se creen y recreen significados y sentidos desde la interacción de docentes y discentes con los medios de comunicación y las redes contextuales emergentes y significativas para el verdadero desarrollo social.

Este trabajo se desarrolló en el contexto educativo universitario de la Universidad Manuela Beltrán (UMB), con una población de estudiantes y docentes, que viven en diferentes regiones de la geografía colombiana y que por primera vez se enfrentan a la educación virtual, en el periodo comprendido entre los años 2012 y 2016. La UMB es una universidad privada de clase media, que ofrece programas en modalidad

Revista de Comunicación de la SEECI. 1576-3420. Marzo, 2017. Año XXI, no 42, pp. 85-118 
Rodríguez García, Y. M. Reconceptualizacion de la educación en la era digital: educomunicacion, redes de aprendizaje y cerebro. Factores claves en los actuales escenarios de construcción de conocimiento

presencial (UMB) y virtual (UMB Virtual), cuyo interés misional es aportar en el crecimiento educativo de jóvenes interesados en profesionalizarse y disminuir la brecha social que ocasiona la falta de educación. Cuenta con una trayectoria de más de 40 años y ofrece más de 30 programas en modalidad virtual, en todos los niveles de formación técnicos, tecnólogos, profesionales y de posgrados que impactan en todo el territorio nacional (Universidad Manuela Beltrán. Quienes somos. 2016).

En los cursos estudiados, se aplicaron estrategias educomunicativas y de participación en redes disruptivas, respecto a lo que "clásicamente" se hace en las clases virtuales y se evalúan variables de perfil cognitivo y motivación. El concepto de educación de los participantes se evalúo de forma mixta (cualitativa y cuantitativa), antes durante y después del proceso experiencial.

¿Cuál es el problema, que suscito este estudio?: los entornos de educación virtual, como los que ofrece la UMB, requieren investigación relacionada con los conceptos que movilizan las prácticas educomunicativas, y de formación de redes, por parte de los estudiantes y docentes y su grado de coherencia con la construcción de conocimiento.

¿Por qué? Aunque las políticas del MEN y MIN TIC Colombianos están de acuerdo con los objetivos de desarrollo sostenible fijados por instancias internacionales que proyectan el desarrollo (Organización de las naciones unidas (ONU), Organización de las Naciones Unidas para la Educación, la Ciencia y la Cultura (UNESCO), Organización de los estados Americanos (OEA), Banco Mundial (BM), Banco Interamericano de Desarrollo (BID), Organización de Estados Iberoamericanos $(\mathrm{OEI})$ ), en lo que se refiere a la educación, tecnología y cultura; las reales prácticas educativas universitarias, distan de estas políticas; pruebas de ello son los resultados académicos en las pruebas internacionales y nacionales que no son los mejores; En las Universidades Colombianas estudiantes y docentes en general tienen expectativas educativas ancladas en conceptos educativos clásicos y modelos transmisionistas, lo que no permite el aprovechamiento de medios ni mediaciones digitales para el avance educativo, del conocimiento y en general el desarrollo. Adicionalmente vivimos un sistema social en conflicto desde hace más de 50 años, lo que invita a repensarnos como seres humanos de forma holística y a involucrar en la educación el cerebro, los avances en neurociencias y psicología, la educación en habilidades para la vida en contexto para posibilitar el avance social.

Lo anterior permitió evidenciar que se requiere investigar a nivel universitario: ¿Cuál es el concepto que tienen los estudiantes y docentes de la educación para la era digital, y el grado de coherencia en las practicas virtuales en aspectos educomunicativos, redes de aprendizaje y neurocognitivos propios de nuestra idiosincrasia.

El estudio parte de la construcción de perfiles, estilos cognitivos y levantamiento de preconceptos en los participantes, seguido de una experiencia educativa disruptiva, frente a los enfoques presenciales educativos, donde priman las actividades dialógicas, con una filosofía educomunicativa, de empoderamiento axiológico, de 
formación de redes colaborativas y lúdicas. Una vez los cursos culminan se establece el postconcepto sobre educación virtual, de los participantes. Las evidencias conductuales que ocurren en las aulas, se registran con análisis de textos, entrevistas, observación y retroalimentaciones recibidas de los participantes. Los datos también permitieron establecer la relación entre la influencia del preconcepto y el desempeño académico, así como también la relación entre motivación y escenarios de aprendizaje educomunicativo

\section{OBJETIVOS}

El objetivo general fue analizar los conceptos de educación en la era digital, las prácticas educomunicativas, de redes de aprendizaje y perfiles cognitivos de una población de estudiantes y docentes neófitos en educación virtual en la Universidad Manuela Beltrán de Bogotá Colombia, en los cursos denominados "Cerebro" y "Diplomado en Fortalecimiento en competencias laborales mediadas por TIC" respectivamente y evidenciar si existe alguna relación con los procesos de construcción de conocimiento.

Se desarrollaron los siguientes objetivos específicos: 1. Establecer el preconcepto de educación en la era digital de estudiantes y docentes en la muestra analizada. 2. Describir las prácticas educomunicativas en los cursos virtuales y su relación con procesos cognitivos. 3. Identificar y describir el uso académico de las redes y su relación con el aprendizaje colaborativo. 4. Constituir los perfiles cognitivos, de los estudiantes y docentes, así como relacionarlos con la construcción de conocimiento. 5. Analizar la relación entre educomunicación y motivación en escenarios digitales. 6. Inferir la importancia del preconcepto de educación digital y los procesos de construcción de conocimiento.

\section{METODOLOGÍA}

3.1 Tipo de Estudio. Este es un estudio de diseño mixto (cuantitativo y cualitativo), analítico, transversal (ya que se examinan una serie de variables en el tiempo) y prospectivo (debido a que su inicio es anterior a los hechos estudiados y los datos se recogen a medida que van sucediendo. $Y$ su desarrollo tiene 2 fases: Fase 1. Intervención a los estudiantes (año: 2012- 2015) y Fase 2. Intervención a los docentes (año: 2016).

3.2 Población. Se estiman 20.000 estudiantes activos y, 26.315 egresados de la Universidad Manuela Beltrán, según la publicación institucional. (Universidad Manuela Beltrán. Quienes somos. 2016).

3.3 Muestra. 4000 estudiantes (jóvenes entre 18 y 24 años), en el periodo comprendido entre 2012 y 2015. Y 300 docentes (adultos mayores de 45 años), en los dos periodos académicos del año 2016. Residentes en varias ciudades, distribuidas en todo el territorio Colombiano. Los estudiantes que participaron cursan 
Rodríguez García, Y. M. Reconceptualizacion de la educación en la era digital: educomunicacion, redes de aprendizaje y cerebro. Factores claves en los actuales escenarios de construcción de conocimiento

una electiva transversal llamada "Cerebro" y los docentes un curso de "Fortalecimiento en competencias digitales" ambos $100 \%$ virtuales, en una plataforma propia que tiene la UMB Virtual denominada Virtual Net 2.0. Y como condición obligatoria esta ser neófito en educación virtual.

\subsection{Análisis cualitativo.}

El abordaje macro cualitativo fue la "Teoría Fundamentada", que permite desarrollar teoría que está fundamentada en la recolección y análisis sistemático de datos. Se partió directamente de los datos y no de supuestos a priori, ni de otras investigaciones o de marcos teóricos existentes. El método general de análisis comparativo constante entre los datos y la teoría emerge (Glaser, Barney G. 1967). La teoría se desarrolló durante la investigación, a través de una continua interpelación entre el análisis y la recogida de datos. (Strauss y Corbin, 1994:273).

Las fuentes primarias que se usaron para recoger la información son: entrevistas, encuestas, análisis de foros, la observación de campo (conducta en el desarrollo de los cursos). Igualmente se usan técnicas interactivas grupales como: trabajo colaborativo, foros de debate, clases en vivo, multimedias interactivas, redes sociales, juegos, y herramientas de programación básica, de inteligencia artificial. Dentro de las fuentes secundarias: periódicos digitales, programas de radio, blogs y videos e interacción con herramientas de la web 2.0. Igualmente puede combinar datos cualitativos con cuantitativos cuando las condiciones e intencionalidad del trabajo lo requería.

\subsection{Análisis cuantitativo.}

Se usó estadística descriptiva y relacional, medidas de tendencia central, para presentar datos agrupados con medias, desviaciones estándar, que se presentan en los gráficos.

\subsection{Análisis por triangulación.}

Cuando se requirió se triangularon datos o métodos, de las diferentes muestras (docentes y estudiantes) y diferentes técnicas (encuestas, entrevistas) estableciendo categorías e indicadores para el análisis. La triangulación se usó para suprimir la incertidumbre de un solo método (Blaikie, 1996)

\section{DISCUSIÓN}

\subsection{Caracterización preliminar de docentes y estudiantes.}

Para analizar las variables de interés fue importante en primera instancia, realizar una caracterización de docentes y estudiantes (mediante encuesta), que incluyera variables personales, de desarrollo escolar ó experiencia docente, según el caso; afinidad por las tecnologías de la comunicación y el preconcepto sobre las practicas académicas en entornos virtuales.

En la Gráfico 1, y 2 están estas caracterizaciones, como datos relevantes, la muestra perteneciente al curso de docentes (Gráfico 1), contiene en mayor proporción 
Rodríguez García, Y. M. Reconceptualizacion de la educación en la era digital: educomunicacion, redes de aprendizaje y cerebro. Factores claves en los actuales escenarios de construcción de conocimiento

docentes hombres mayores de 50 años, con más de 11 años de experiencia en docencia y con un concepto negativo de la educación virtual (64\% reticencia). Por su parte la muestra de estudiantes (Gráfico 2), se observa que está compuesta sobre todo por mujeres, jóvenes, cuya escolaridad universitaria es de máximo 3 años y con un preconcepto aceptable de la educación virtual (68\% aceptación).

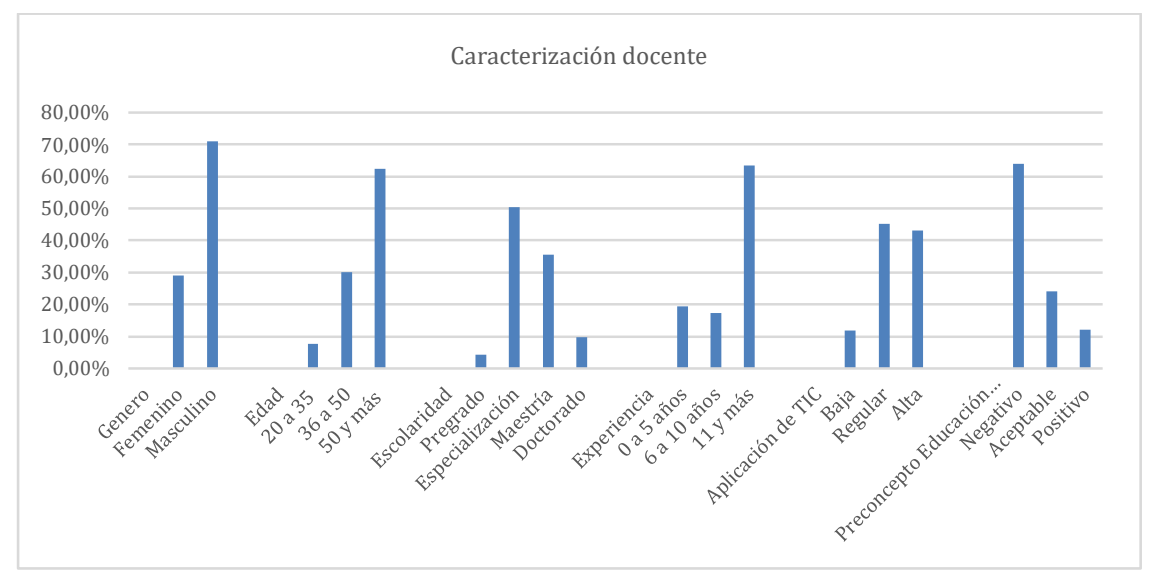

Gráfico 1: Caracterización docente, variables: genero, edad, escolaridad, experiencia docente, uso de las TIC y preconcepto de la educación virtual n: 300.

Elaboración propia

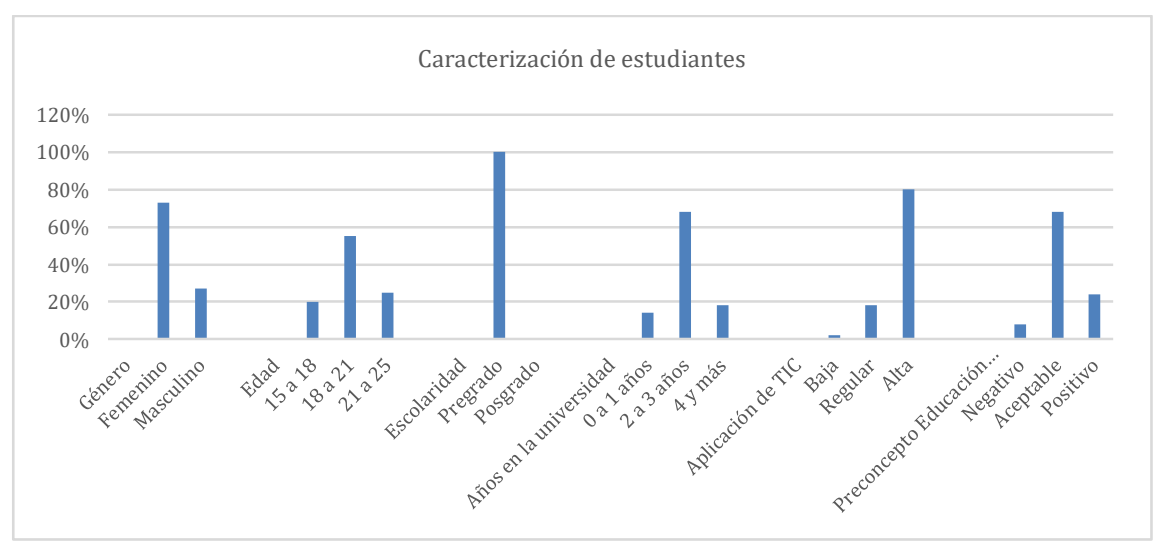

Gráfico 2: Caracterización de estudiantes variables: genero, edad, escolaridad, experiencia docente, uso de las TIC y preconcepto de la educación virtual (n: 3643). Elaboración propia

\subsection{Estilo cognitivo de estudiantes y docentes.}


Rodríguez García, Y. M. Reconceptualizacion de la educación en la era digital: educomunicacion, redes de aprendizaje y cerebro. Factores claves en los actuales escenarios de construcción de conocimiento

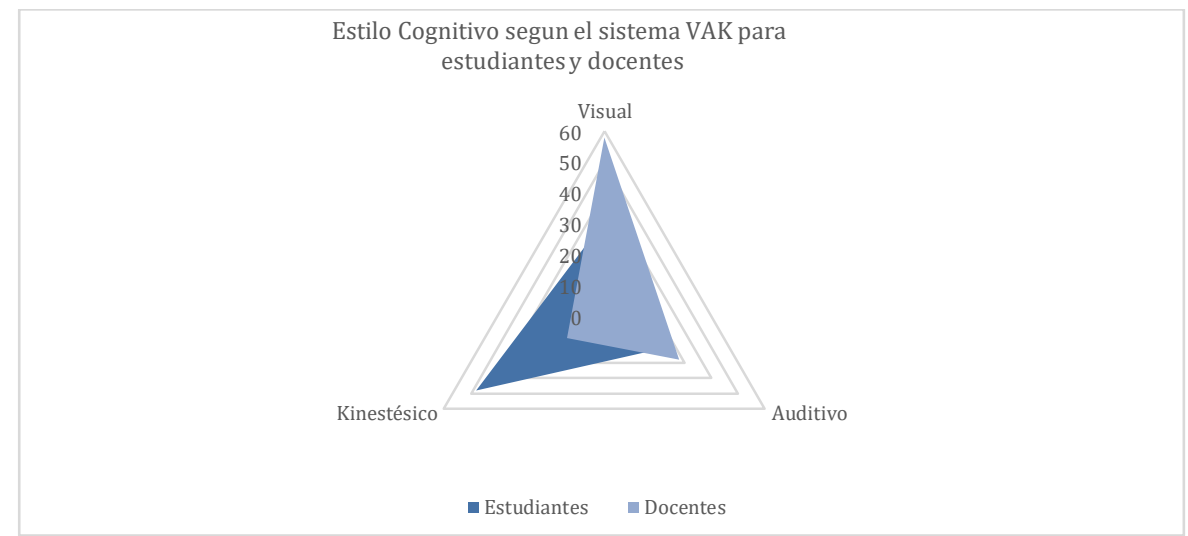

Gráfico 3: Estilo cognitivo según el modelo V.A.K. para docentes y estudiantes. Elaboración propia

Se evaluaron los estilos cognitivos de la muestra de estudiantes y docentes, basándonos en el modelo V.A.K. Visual, Auditivo y Kinestésico (Dunn y Dunn, (1978), que muestra la preferencia para aprender ó representación preferida (Visual: prefiere el canal visual para representar la información y almacenarla, con mayor rapidez y abstracción; Auditivo: usa la audición para memorizar y es secuencial; y el Kinestésico: asocia la información y la procesa mediante sensaciones o movimientos).

Este punto de partida fue fundamental para la planeación pedagógica de los cursos, junto con el perfil que se estableció, (en Gráfico 1 y 2). De esta forma se realizó el diseño pedagógico y didáctico de los cursos respectivos, para enriquecer la práctica educativa. Conocer el estilo cognitivo permitió en adelante establecer el grado de asociación de estos, con respecto a la evaluación de aprendizajes usando estadísticos descriptivos y de correlación. En la muestra de estudiantes predominó el kinestésico y visual frente a la muestra de docentes donde predomina el visual auditivo

Teniendo en cuenta que el género femenino es predominante en la muestra de estudiantes, se pudo discutir como optimizar los recursos en el microcurriculo, generando actividades multitarea y otras de focalización de atención. Dado que los cerebros de las mujeres pueden prestar atención a varias cosas con mayor eficiencia que los hombres Baron-Cohen, S. (2003). Y teniendo en cuenta las características de los docentes la complejidad en tareas lúdicas disminuyo y aumento la complejidad y el uso audios, lecturas y videos educativos, en ambos casos bajo el esquema del aprendizaje crítico y los principios educomunicativos.

\subsection{Preconcepto de la educación virtual de estudiantes y docentes}

Mediante instrumentos de encuestas y entrevistas se corroboro la información inicial sobre el preconcepto de educación en entornos digitales de estudiantes ( $\mathrm{n}: 1000$, participantes en la en encuesta y entrevista, de forma aleatoria, ventana de tiempo una semana) y docentes ( $\mathrm{n}: 100$ participantes en la en encuesta y entrevista, de forma aleatoria, ventana de tiempo una semana). En general la el preconcepto de los 
Rodríguez García, Y. M. Reconceptualizacion de la educación en la era digital: educomunicacion, redes de aprendizaje y cerebro. Factores claves en los actuales escenarios de construcción de conocimiento

docentes no es positivo frente a la educación virtual, incluso manifiestan temor de perder su trabajo y ser "remplazados por maquinas", saben que es una realidad presente en la cultura pero la aíslan de sus prácticas educativas en una gran proporción, sin embargo algunos docentes próximos a jubilarse desean aprender a usar las tecnologías y en general están abiertos a las posibilidades y con menos temores, que los docentes más jóvenes.

El preconcepto de la educación virtual de los estudiantes en general es positivo, siendo nativos digitales, no conciben porque los docentes son tan renuentes al uso de tecnologías para las prácticas académicas. Aunque refieren saber usar los dispositivos, sienten temor por algunas situaciones de la red y prefieren sentirse agobiados con tanta información y poca formación para evaluarla. De forma tal que este panorama refiere una asincronía (entre estudiantes y docentes) de perfiles cognitivos, uso de la tecnología y comprensión profunda de lo que puede significar aprender y enseñar en la era digital.

La construcción de conocimiento, en nuestras instituciones educativas, se sigue evaluando por las acciones de: reconocer, almacenar, recuperar, comprender, organizar y usar la información, que comúnmente son usados en las evaluaciones académicas, como verbos que evidencian acciones de los estudiantes y han sido descritos en diferentes taxonomías de verbos para la construcción de objetivos y competencias académicas. El cambio puede partir de las prácticas docentes, incluyendo por ejemplo verbos o acciones propias, de la sociedad red en las estructuras de sus currículos y sus didácticas y haciendo una apertura mental a otras prácticas pedagógicas que incluyan variables de la revolución digital, los macro datos, las redes y sus desarrollos aplicados a la educación; estas dinamicas nos invitan a todos comunicarnos, aprender, desaprender y educar de una manera distinta y a comprender estos procesos desde nuestra biología para potenciar las mejores estrategias para educar el cerebro.

El encuentro con estos nuevos paradigmas educativos virtuales, ubicuos y en red, de inteligencia colectiva (Lévy, Pierre. 2004), nos brinda desafíos y oportunidades para analizar prácticas educativas (función cerebral: cognición) y comunicativas (función cerebral: lenguaje) y su posible relación con los procesos mentales de gestión de la información y construcción del conocimiento, que emergen en el entorno académico digital.

\subsection{Experiencia de los estudiantes en el curso transversal electivo de "Cerebro".}

La UMB Virtual, ofrece la electiva transversal virtual, de cerebro, a estudiantes de todas las carreras y en todo el territorio nacional. Esta asignatura es el escenario experiencial que se analizará en esta investigación, y fue diseñada desde lo pedagógico y didáctico por la autora de la presente investigación.

El curso de Cerebro es un espacio de autoconocimiento como seres humanos, del órgano más enigmático que se conoce: el cerebro; en aspectos biológicos, físicos, químicos, psicológicos y funcionales, básicos, como centro de control e integración;

Revista de Comunicación de la SEECI. 1576-3420. Marzo, 2017. Año XXI, no 42, pp. 85-118 
así como en otros aspectos más aplicados cómo las funciones superiores complejas como el aprendizaje y la memoria, y la conciencia, los mecanismos cerebrales de comportamiento, emoción, motivación, demencia, dolor, funciones cerebrales en la comunicación, el lenguaje, la sexualidad y los estados extremos de actividad cerebral como son la epilepsia, las psicosis y el sueño. Está concebido con una filosofía educomunicativa por lo que posibilita la interacción con juegos y demos sobre inteligencia artificial, realidad virtual y realidad aumentada que le permitirán integrar los conocimientos teóricos con aplicaciones reales de su entorno.

Entre los años 2012 a 2015, tuvieron la oportunidad de tener esta experiencia educomunicativa y de redes 3643 estudiantes de todo el territorio nacional. (Gráfico 4)

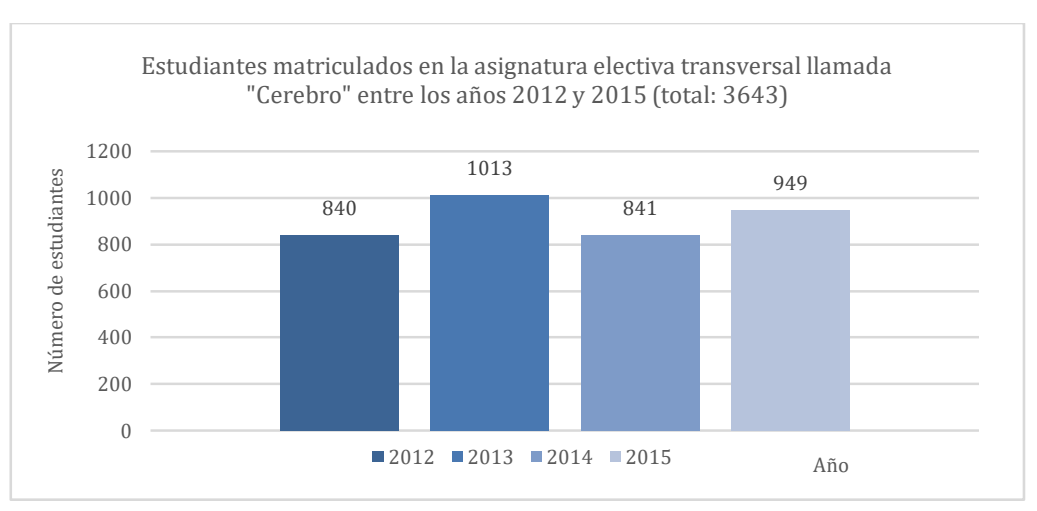

Gráfico 4: Número de eestudiantes matriculados en la asignatura de cerebro entre el año 2012 y 2015. Elaboración propia

El curso de cerebro, cuenta con 5 módulos que en su orden atienden a resolver estas 5 preguntas: ¿Cómo evolucionó el cerebro?, ¿Cómo está organizado?, ¿Cómo funciona?, ¿Cuáles son las funciones cerebrales complejas?, ¿Cuáles son los últimos avances en neurociencias, inteligencia artificial, realidad virtual y realidad aumentada?

Metodológicamente el proceso de aprendizaje fue mediado on line, en la plataforma Virtualnet 2.0, que proporciona una experiencia interactiva e intuitiva, en la cual se vivencia el aprendizaje apoyado en la web 2.0, el trabajo colaborativo, las redes sociales y la lúdica, la educomunicación. Cuenta con elementos gráficos, de PDF y multimedia interactiva por cada módulo, y juegos, que potencian el conocimiento. Es importante resaltar que en cada tema de los módulos al estudiante se le ofrecen varias posibilidades para escogencia del subtema que más le interese trabajar y sobre el cual tenga más afinidades y sea más significativo según su profesión y la región geográfica donde habite. Lo que redunda en obtención de notas en promedio muy superior a otras asignaturas electivas (Gráfico 5) 
Rodríguez García, Y. M. Reconceptualizacion de la educación en la era digital: educomunicacion, redes de aprendizaje y cerebro. Factores claves en los actuales escenarios de construcción de conocimiento

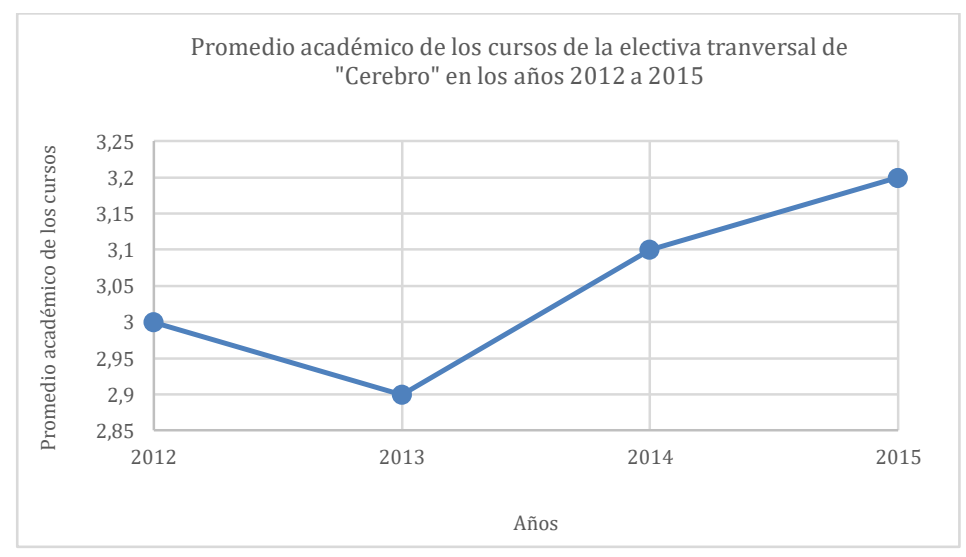

Gráfico 5: Promedio académico neto en los cursos de cerebro entre el año 2012 y 2015. Elaboración propia

La evaluación de aprendizajes mediados por experiencias educomunicativas, (gráfico 6) muestra resultados muy positivos con el empoderamiento de los estudiantes en actividades de radio (74\%), encuentros sincrónicos (80\%), y juegos (72\%). Mientras que actividades que involucraban la producción de videos y de material interactivo de la web 2.0, presentaron una aprobación media, los peores resultados con los alumnos están en el desarrollo de actividades de inteligencia artificial (40\%), que involucraban habilidades de programación.

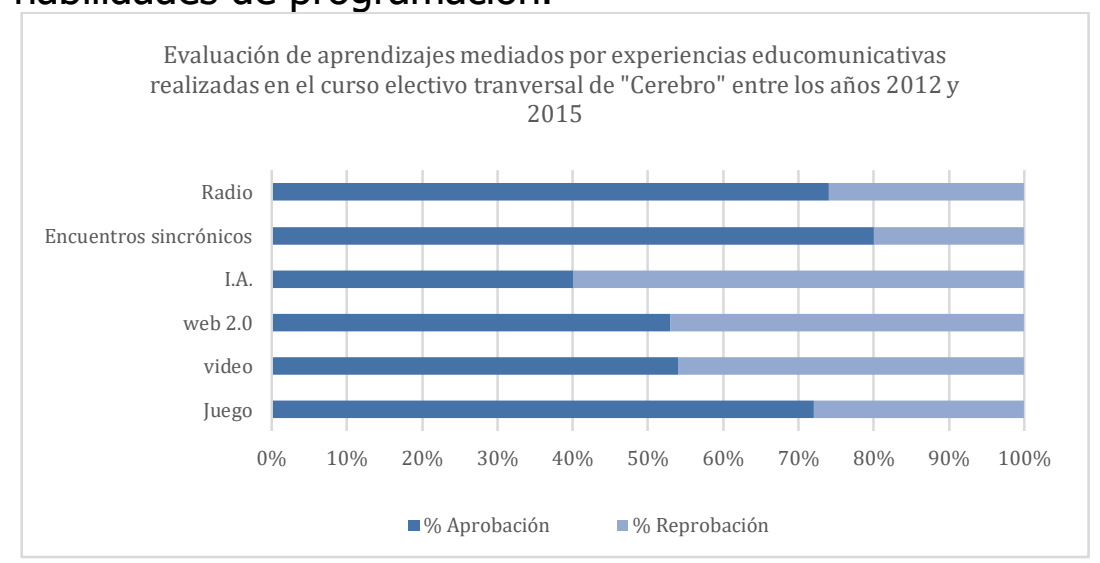

Gráfico 6: Evaluación de aprendizajes mediados por experiencias educomunicativas realizadas en el curso electivo transversal de "Cerebro" entre los años 2012 y 2015. Elaboración propia

Al evaluar si habían diferencias en la ponderación evaluativa de las diferentes actividades de corte educomunicativos (participación en juegos, producción de videos, actividades usando la Web 2.0, de Inteligencia artificial, encuentros sincrónicos, y participación en programas de radio) en el tiempo no se encontraron diferencias significativas en los años analizados. (Gráfico 7).

Uno de los objetos de la experiencia ofrecida al curso era experimentar con actividades que centraran y empoderaran al estudiante de su proceso cognitivo y crítico; como propone Kaplún en la corriente pedagogía de la comunicación (Kaplún, M.2010), y acorde a los desafíos de este mundo conectado en la red de redes de 
internet, fue que se realizó la concepción didáctica, de esta experiencia en la clase de cerebro, que atiende a la propia interpretación de la relación entre comunicación y educación inmersa en esta cultura y sociedad colombiana. Según Barbas (2012) citando a Kaplun (1998), que a cada manera de concebir la educación y la sociedad le corresponde una práctica de comunicación y que existen prácticas educomunicativas que no corresponden con las reales concepciones de educación. Según los resultados reflejados en la graficas 6 y 7 fueron exitosas desde el punto de vista de la evaluación de aprendizajes. Al hacer triangulación de la información que se tenía en los diálogos, foros y correos la receptividad y predisposición por participar fue excelente.

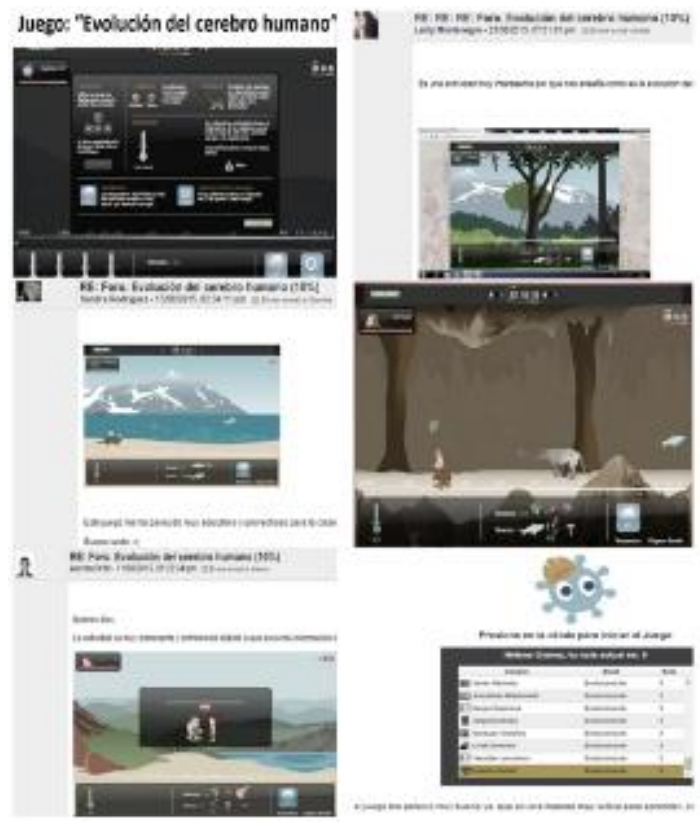

Imagen 1: Evidencia del juego de evolución de cerebro, una OVA interactiva y auto evaluable. Recopilación de imágenes del aula http://plataforma.umb.edu.co/virtualnet/homec.php

En la imagen 1 se visualizan imágenes de la primera actividad interactiva del curso de cerebro, que correspondía al juego interactivo y auto calificable. El estudiante en este juego comenzaba con un avatar de célula, el cual al superar obstáculos ambientales, depredadores y contestar las preguntas acertadamente iba cambiando, en diferentes organismos donde interactuaba con información y preguntas de la evolución del cerebro de estos organismos, hasta llegar a los primates, homínidos y homo sapiens; el juego finalizaba con el embarazo de una (humana) Homosapiens sapiens y las explicaciones sobre neurodesarrollo fetal, un tema que ofrecido con esta interacción resultaba entendible y significativo para la mayoría de estudiantes que pertenecían a diferentes carreras por ende tenían diferentes intereses. La evaluación cualitativa era en tiempo real y el estudiante podía parar y proseguir cuando quisiera. La retroalimentación de esta actividad, así como la participación en la clase aumentaba de forma significativa (imagen 5), la participación en el foro de 
Rodríguez García, Y. M. Reconceptualizacion de la educación en la era digital: educomunicacion, redes de aprendizaje y cerebro. Factores claves en los actuales escenarios de construcción de conocimiento

discusión del tema también se evidencio en todos los cursos dinámica y con un nivel de profundidad mayor que otras actividades que no involucran lúdica.

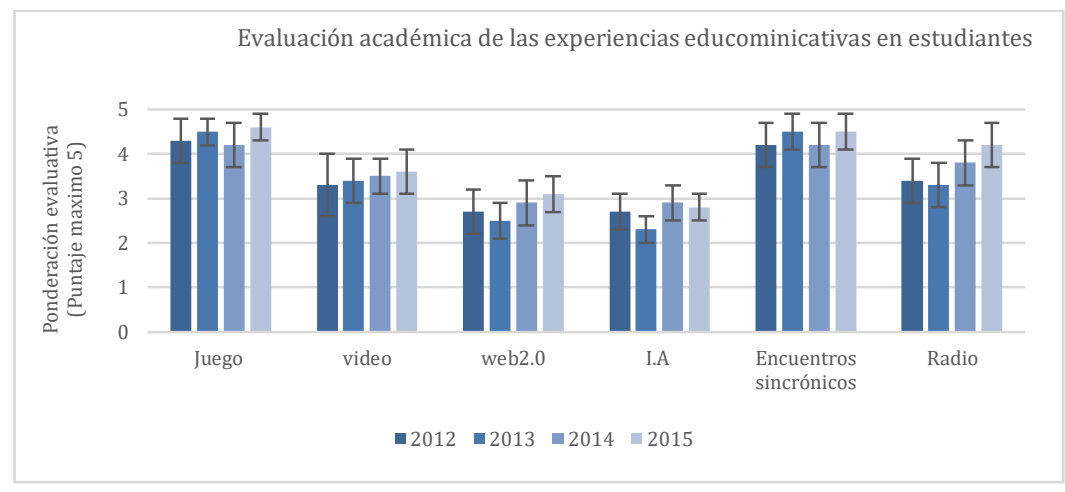

Gráfico 7: Evaluación académica de las experiencias educomunicativas en estudiantes en años 2012 a 2015. Elaboración propia

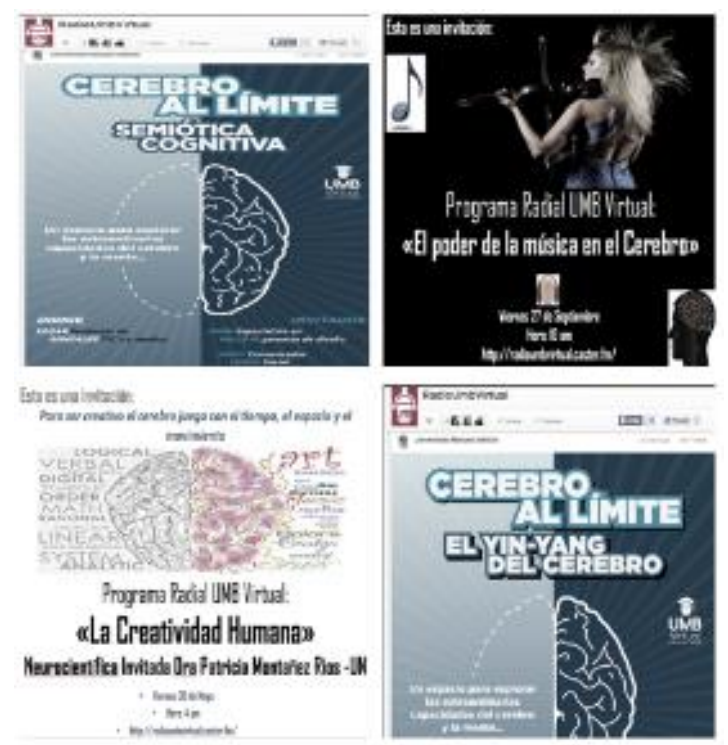

Imagen 2: Evidencia de algunos programas de radio ofrecidos como estrategia académica, para generar debates en los foros con posibilidad de participación en directo. Recopilación de imágenes del aula http://plataforma.umb.edu.co/virtualnet/homec.php

Otro tipo de interacción de corte educomunicativo fueron los programas de radio hechos con la participación de los estudiantes y comunicación con sus pares en tiempo real, por teléfono, chat y redes sociales (un ejercicio similar al de Jose Celestin Freinet, pero con radio). En la imagen 2 se muestran algunos de los programas de radio que realizaron los estudiantes, ellos mismos escogían la temática por encuesta o dialogo en el foro del curso. Estos espacios fueron denominados disruptivos por la comunidad académica, y generaron la apertura de la radio universitaria de UMB Virtual, con la compra de un canal propio, pues los primeros 
Rodríguez García, Y. M. Reconceptualizacion de la educación en la era digital: educomunicacion, redes de aprendizaje y cerebro. Factores claves en los actuales escenarios de construcción de conocimiento

programas los estudiantes los realizaron con servidores gratuitos de la red. (Imagen 2 , algunos ejemplos de programas de radio emitidos por los estudiantes y para los estudiantes) la interacción en este escenario evidencia una excelente evaluación de aprendizajes que fue progresiva en el tiempo (año 2015: 4.2 promedio general de los cursos en esta actividad). (Gráfico 6 y 7 ).

Dentro de las experiencias educativas ofrecidas a los estudiantes también, estuvieron el uso de las redes sociales y ejercicios de trabajo colaborativo, como se nota en el gráfico 8, se evaluaron los aprendizajes en las redes sociales Facebook, twitter y trabajo colaborativo, con una herramienta desarrollada para esto en la plataforma Virtual Net 2.0, que evidenciaba el proceso del trabajo conjunto (mediante video, que captaba todas las entradas y actividad de los participantes) y no solamente el producto colaborativo.

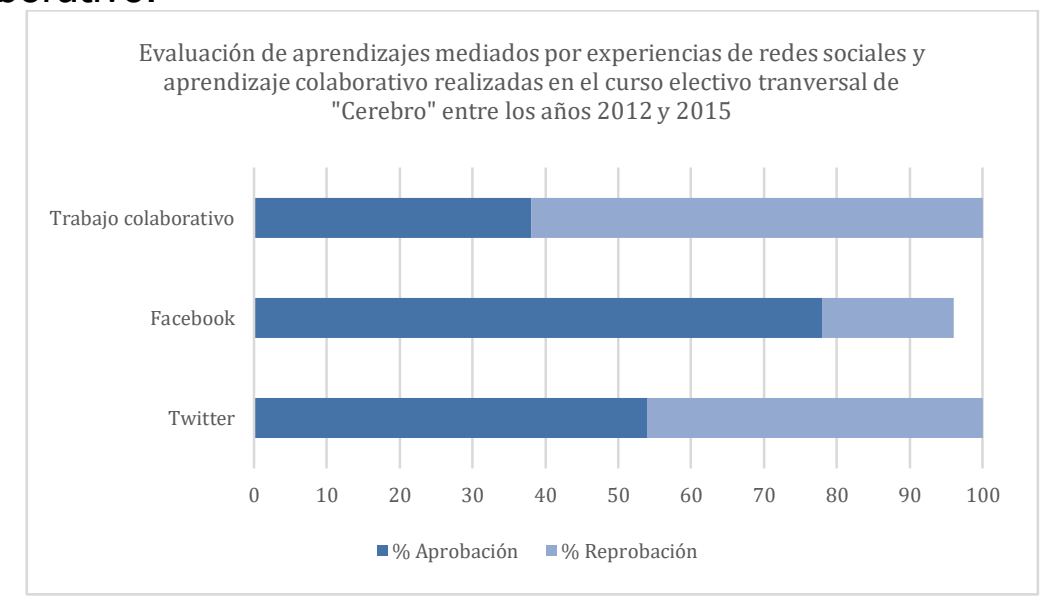

Gráfico 8: Evaluación de aprendizajes mediados por experiencias de redes sociales y aprendizaje colaborativo realizadas en el curso electivo transversal de "Cerebro" entre los años 2012 y 2015. Elaboración propia.

Los resultados de la actividad en redes sociales en el periodo analizado de 4 años, sugieren una gran aceptación al trabajo en la red social Facebook $(78 \%)$, seguida de twitter (54\%) y menor habilidad (38\%), para las actividades de trabajo colaborativo. Estos resultados pueden deberse a la poca experticia de los estudiantes en este tipo de actividades colaborativas, en entornos virtuales. Según Siemens las personas requieren un tiempo en adquirir un espacio de confianza. Siemens, G (2010), es decir los estudiantes no se han empoderado del concepto de una actividad colaborativa en la red y como gestionarse. 


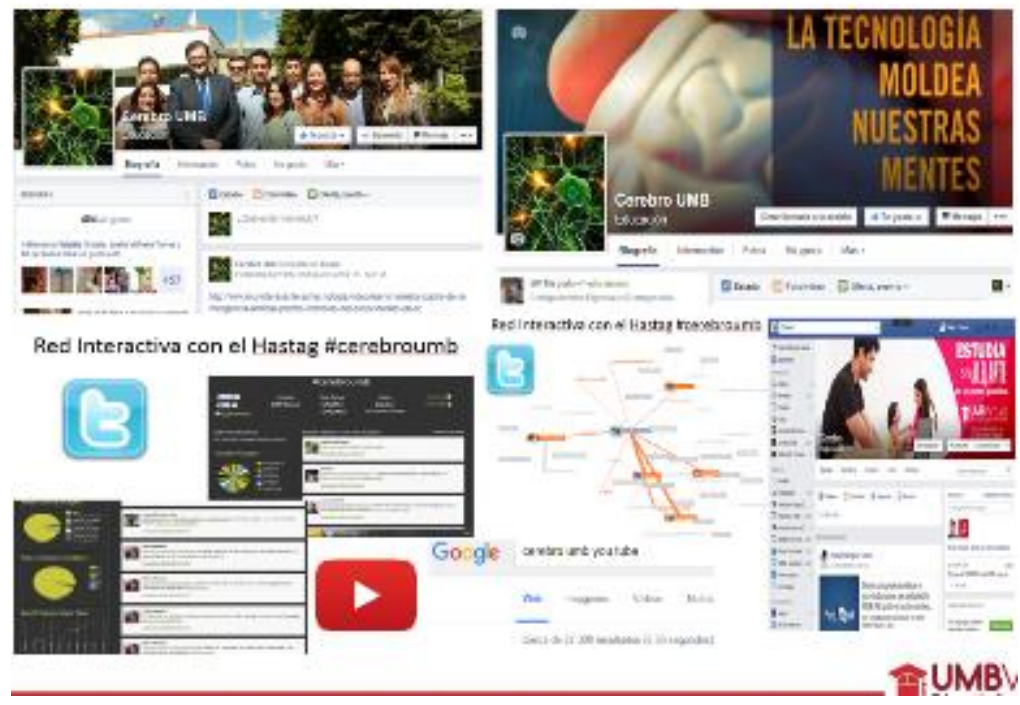

Imagen 3: Evidencia del trabajo en redes sociales Facebook y Twitter; Algunos análisis por mentionmap). Recopilación de imágenes del aula http://plataforma.umb.edu.co/virtualnet/homec.php

La imagen 3 presenta evidencia, de algunas interacciones de las redes sociales en este curso masivo, inicialmente la página de cerebro se creó en la cuenta personal de la docente y al ver el éxito y aumento de la permanecía en este curso la universidad creo páginas de Facebook para las asignaturas que quisiesen media $r$ sus aprendizajes con esta red social. Este hecho traspaso el aula de cerebro y se constituyó en un movimiento de educación con uso de redes sociales en toda la Universidad, pues los estudiantes comenzaron a demandar estos espacios en otras asignaturas (Imagen 3).

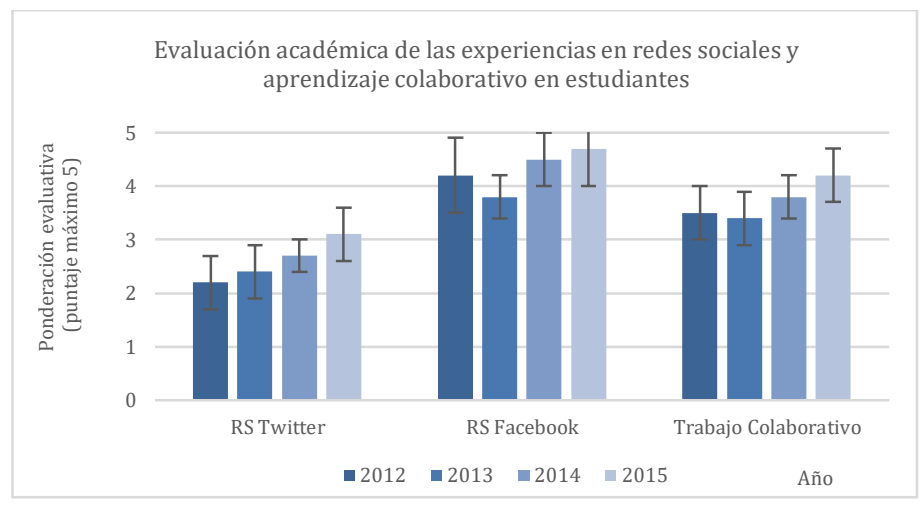

Gráfico 9: Evaluación académica de las experiencias en redes sociales y aprendizaje colaborativo en estudiantes. Elaboración propia

En cuanto a la evaluación académica de las experiencias en redes sociales y aprendizaje colaborativo (Gráfico 9), se nota una mejoría del desempeño en el tiempo, esto se debe al empoderamiento que se ha dado en nuestro país de la redes sociales (Twitter en 2015: 3.1/5 y Facebook en 2015: 4.7/5); en cuanto al trabajo 
Rodríguez García, Y. M. Reconceptualizacion de la educación en la era digital: educomunicacion, redes de aprendizaje y cerebro. Factores claves en los actuales escenarios de construcción de conocimiento

colaborativo hay un mejor desempeño en el aprendizaje en el año 2014 (3.8/5) y 2015 (4.2/5.0).
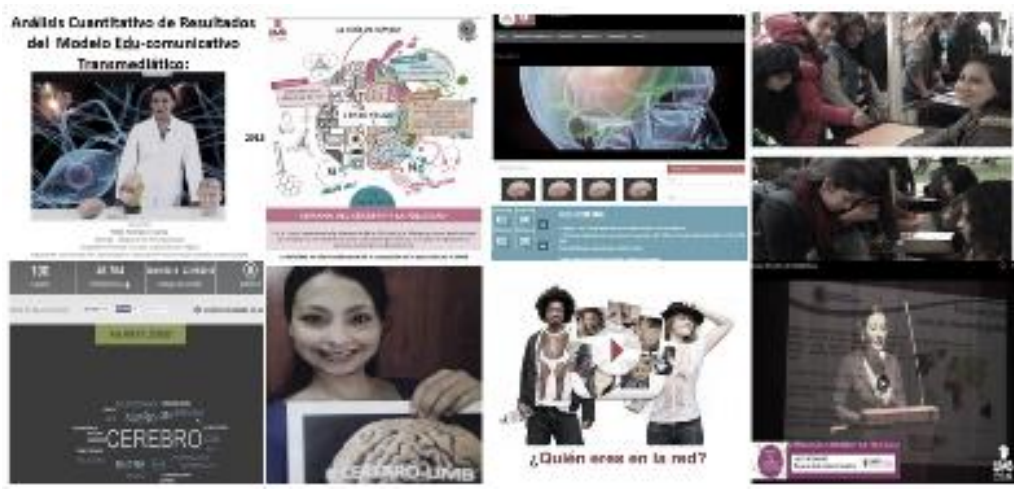

Imagen 4: Evidencia de estrategias de aprendizaje sincrónicas presenciales: Semana del Cerebro, clases en directo, diálogos, dialéctica en twitter, encuentros académicos, días de retos mentales. Recopilación de imágenes del aula

http://plataforma.umb.edu.co/virtualnet/homec.php

La plataforma Virtual Net 2.0 permitía conocer los informes de actividad en cuantos a ingresos y contenidos visitados durante la experiencia de los cursos. Se evidencio (Imagen 5) la gran actividad en cuanto a la cantidad de contenidos visitados que daban cuenta de la interacción en este curso respecto a otros cursos referentes, que presentan poca interacción. Se observa un cambio de conducta de los usuarios en las primeras semanas de clase, con pocas interacciones, pero una vez se cursaba el juego auto evaluable que era primera actividad, cambia el comportamiento interactivo en este curso y aumentaba la motivación de los participantes hacia esta electiva. Los resultados cuantitativos se corroboraron con observaciones, entrevistas y retroalimentaciones. 
Rodríguez García, Y. M. Reconceptualizacion de la educación en la era digital: educomunicacion, redes de aprendizaje y cerebro. Factores claves en los actuales escenarios de construcción de conocimiento
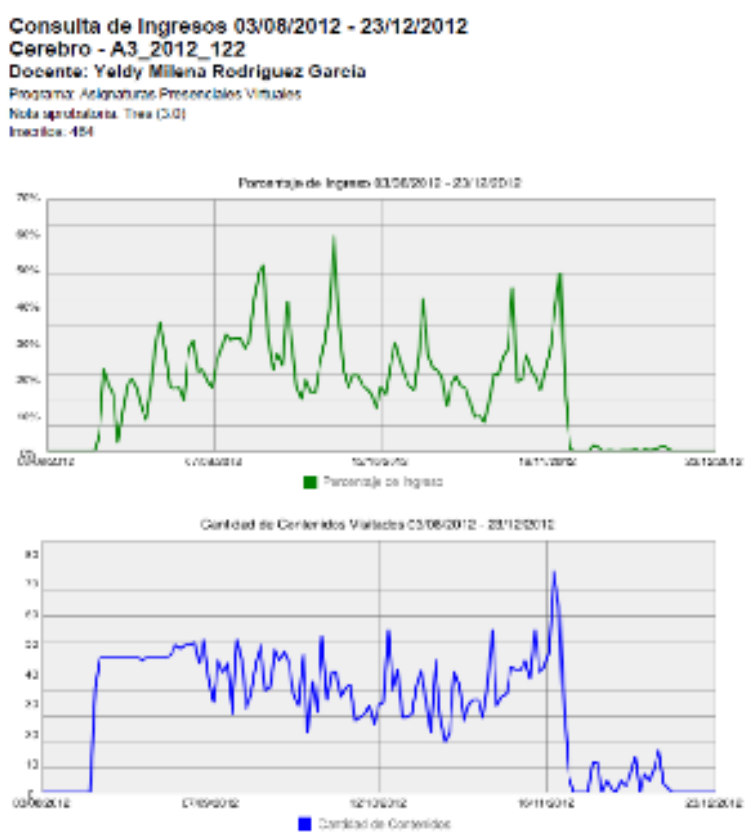

\section{.}
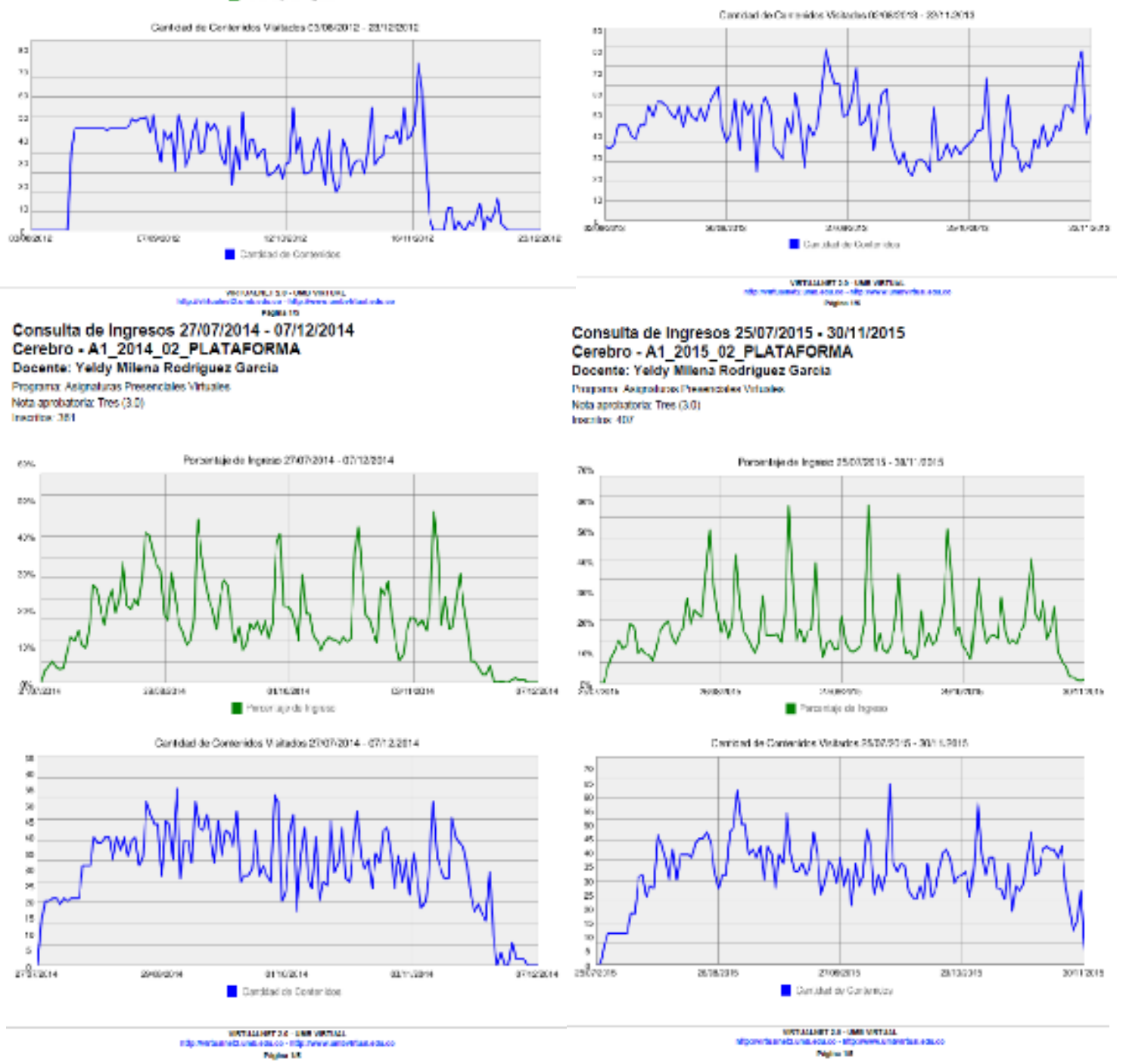

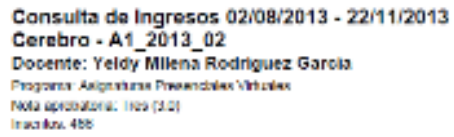

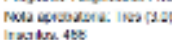
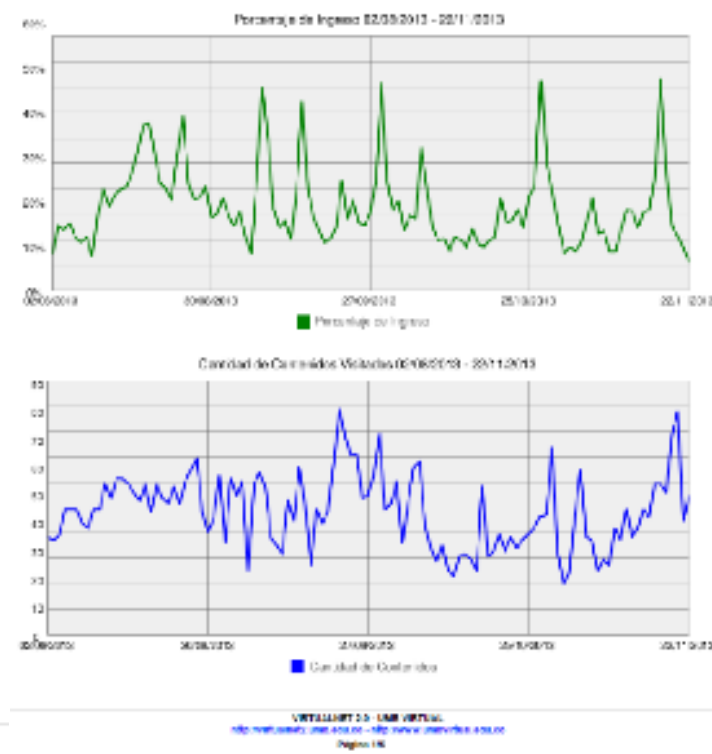

Consulta de Ingresos 25/07/2015 - 30/11/2015

Cerebro-A1_2015_02_PLATAFORMA

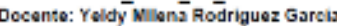

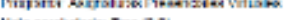
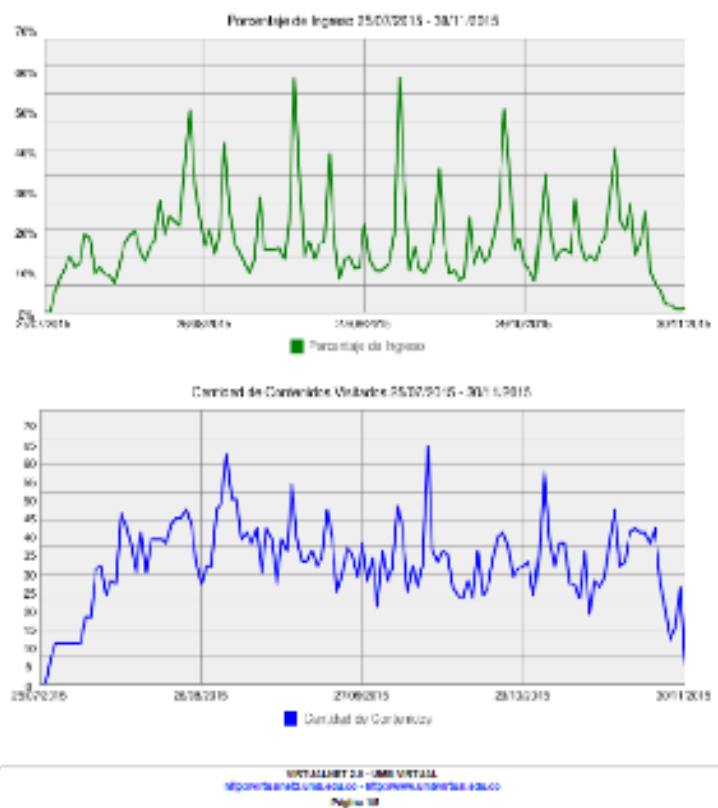

Imagen 5: Comportamiento de ingresos y contenidos visitados.

Recopilación de imágenes del aula

http://plataforma.umb.edu.co/virtualnet/homec.php

\subsection{Experiencia de los docentes en el curso electivo "Diplomado en fortalecimiento en competencias laborales mediadas por TIC".}


Rodríguez García, Y. M. Reconceptualizacion de la educación en la era digital: educomunicacion, redes de aprendizaje y cerebro. Factores claves en los actuales escenarios de construcción de conocimiento

Por otro lado, la experiencia que se realizó con los docentes fue en un diplomado electivo para fortalecer las competencias laborales mediadas por la tecnología, en este participaron 300 docentes ubicados en diferentes regiones de la geografía del país. En atención a que tuviésemos variables comparables se organizó un micro currículo con actividades educomunicativas, de redes sociales y aprendizaje colaborativo, igual que con el curso de los estudiantes, pero ofreciendo mediaciones acorde al estilo de aprendizaje.

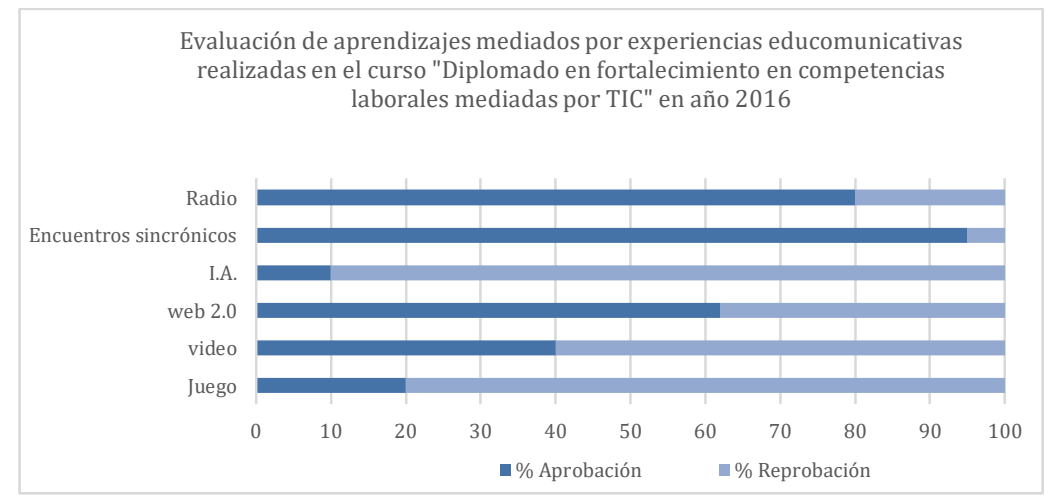

Gráfico 10: Evaluación de aprendizajes mediados por experiencias educomunicativas realizadas en el curso "Diplomado en fortalecimiento en competencias laborales mediadas por TIC" ofrecido a docentes en año 2016. Elaboración propia

En la Gráfico 10 se muestran las experiencias educomunicativas ofrecidas a los docentes, se destaca una mayor receptividad para los encuentros sincrónicos $(95 \%)$, los programas de radio $(80 \%)$ y deficiencias en participación en juegos $(20 \%)$ y videos académicos (40\%), y muy poco avance en actividades de programación (10\%). Comparando con el comportamiento de los estudiantes son resultados contrarios, la muestra de docentes analizada prefiere participar en actividades cercanas a lo que conocen que es el modelo d educación tradicional y presencial, nótese la alta participación en los encuentros sincrónicos (95\%). Tal como lo reporta Morín en 2000, informe a la UNESCO, existen algunos saberes necesarios para la educación del futuro, que los docentes estamos en mora de liderar, véase baja tasa de aprobación en actividades de juegos, videos y programación, en los cuales esta muestra de 300 docentes tiene la oportunidad de fortalecer. (Morin, E. 2000).

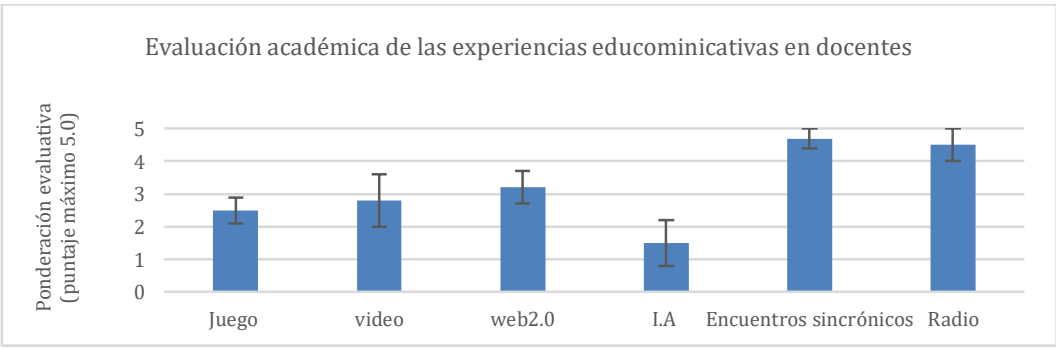

Gráfico 11: Evaluación académica de las experiencias educomunicativas en docentes. Elaboración propia 
Rodríguez García, Y. M. Reconceptualizacion de la educación en la era digital: educomunicacion, redes de aprendizaje y cerebro. Factores claves en los actuales escenarios de construcción de conocimiento

La evaluación académica (Gráfico 11), ratifica los resultados de la experiencia y las evidencias cualitativas.

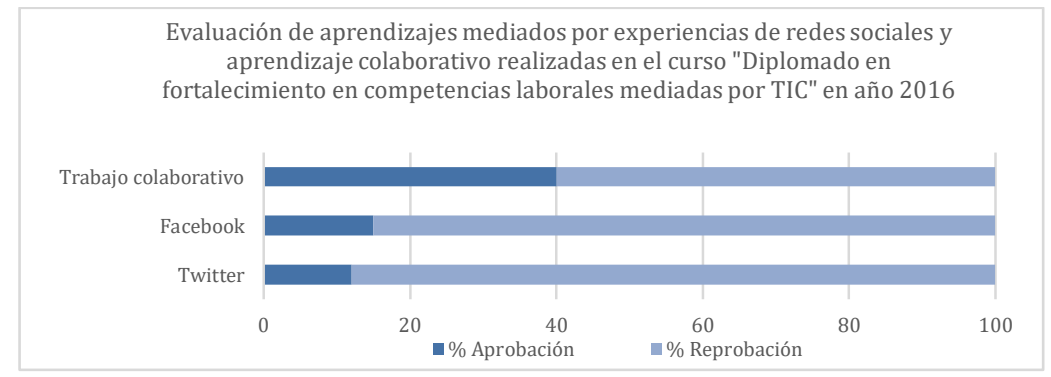

Gráfico 12: Evaluación de aprendizajes mediados por experiencias de redes sociales y aprendizaje colaborativo. Elaboración propia.

La evaluación de aprendizajes mediados por experiencias de redes sociales y aprendizaje colaborativo (gráfico 12) realizadas a los docentes del curso "Diplomado en fortalecimiento en competencias laborales mediadas por TIC" en año 2016, para docentes sugieren un buen desenvolvimiento en actividades de trabajo colaborativo (40\% de docentes aprobaron) a diferencia de lo ocurrido con los alumnos, este es un punto muy positivo para los docentes y puede articularse fácilmente a sus didácticas en adelante. Los docentes analizados muestran debilidades en redes sociales. (15\% en faceboock y $12 \%$ en Twitter), pero reportan en el dialogo y las entrevistas, el deseo de aprender a gestionar sus clases en las redes.

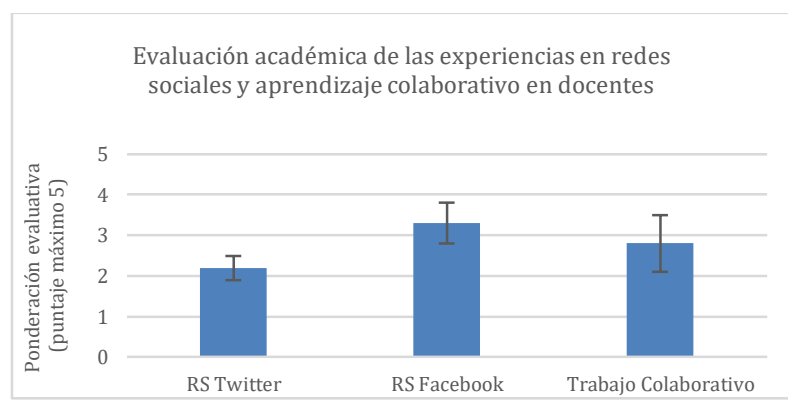

Gráfico 13: Evaluación académica de las experiencias en redes sociales y aprendizaje colaborativo en docentes. Elaboración propia

El Gráfico 13 corrobora cuantitativamente, los resultados anteriores, sobre la evaluación académica en estos 3 entornos.

Ya a principios del milenio Castells, en su libro La era de la información, vislumbra esta realidad con tantas cualidades como retos en formación de docentes (Castells, 2000). Este punto de partida con la visión de Castells, puede ser pilar para iniciar a tranformar el concepto de educación en entornos digitales por parte de los docentes. Seguramente con esta experiencia el discurso TICs deja de ser letra muerta y se 
convierte en un eje motivador y retador para el docente. En atención a la distribución de los docentes que tomaron el diplomado, podemos hacer una proyección del estado de formación y competencias digitales de los docentes a mayor nivel, ya que estos docentes estaban distribuidos a nivel nacional.

Con el ánimo de monitorear la experiencia docente en temas como: las ventajas, el desarrollo de competencias, que valoraran la experiencia, la significancia, la motivación, y para valorar aspectos de metodología y accesibilidad se realizó un instrumento para evaluar la experiencia de los docentes de este diplomado, a la que se invitó a los 300 docentes, pero que contestaron 175 docentes, pues no era de carácter obligado, se presentan algunos resultados en las gráficos 14 a 16:

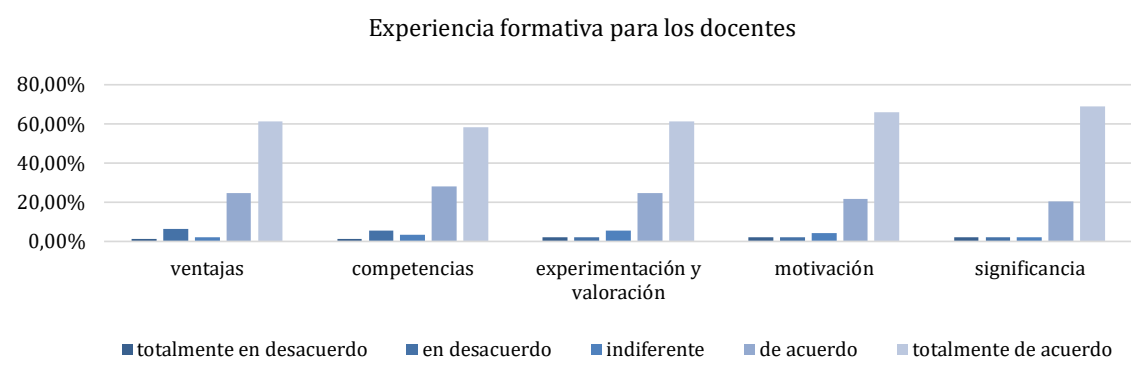

Gráfico 14: Estilo Experiencia formativa para los docentes. Elaboración propia

Cuando se les pregunta a los docentes sobre su experiencia formativa, (Gráfico 14) en el diplomado virtual, en las categorías: ventajas para el trabajo docente, desarrollo de competencias tecnológicas, experimentación y valoración del curso, motivación a seguir realizándolo, y significancia en su desarrollo personal, reportan estar totalmente de acuerdo con el aporte del curso en estos temas.

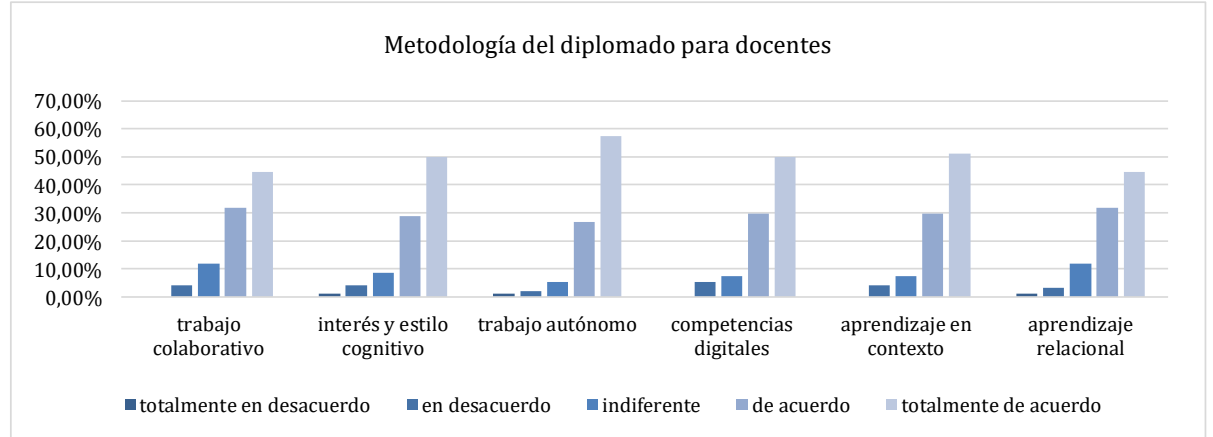

Gráfico 15: Metodología del diplomado para docentes. Elaboración propia En la indagación a los docentes sobre su la pertinencia de la metodología, (Gráfico 15) en el diplomado virtual, en las categorías: trabajo colaborativo, interés y estilo cognitivo, trabajo autónomo, competencias digitales, aprendizaje en contexto y aprendizaje relacional, también reportan estar totalmente de acuerdo con el aporte 
Rodríguez García, Y. M. Reconceptualizacion de la educación en la era digital: educomunicacion, redes de aprendizaje y cerebro. Factores claves en los actuales escenarios de construcción de conocimiento

del curso en estos temas, como tendencia al "totalmente de acuerdo" se observa en las columnas. (Gráfico 15)

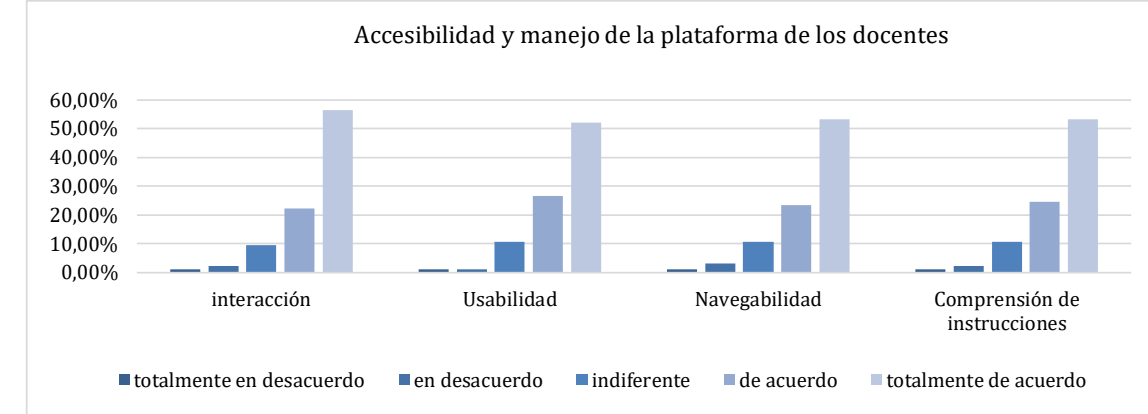

Gráfico 16: Accesibilidad y manejo de la plataforma de los docentes. Elaboración propia

Sobre la accesibilidad y manejo de la plataforma, en categorías como: interacción, usabilidad, navegabilidad y comprensión de instrucciones, también los 175 docentes reportan estar totalmente de acuerdo con el funcionamiento en estos ítems (Gráfico 16).

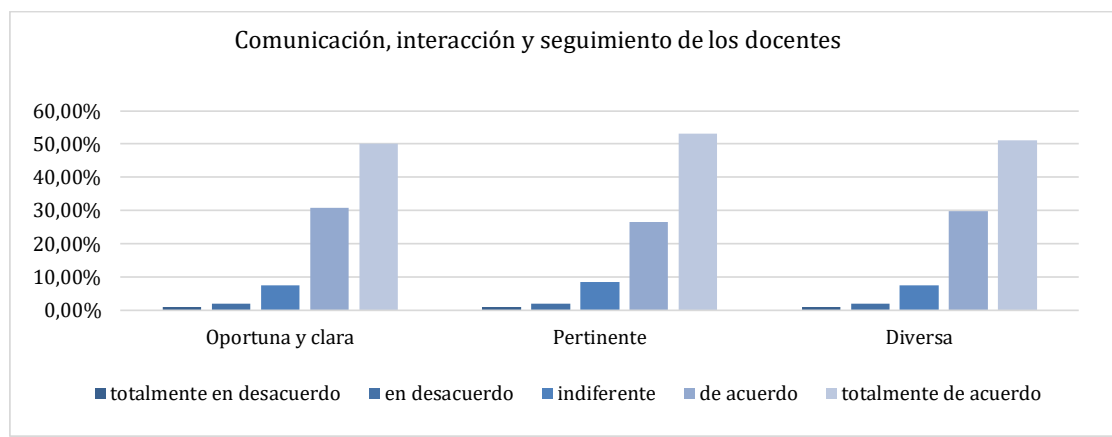

Gráfico 17: Comunicación, interacción y seguimiento de los docentes. Elaboración propia

Cuando se pregunta los docentes por temas de comunicación oportuna, facilidad de interacción y acompañamiento y seguimiento al proceso del diplomado, los encuestados dicen estar en general de acuerdo o totalmente de acuerdo con que estos procesos tuvieron un buen desarrollo. (Gráfica 17)

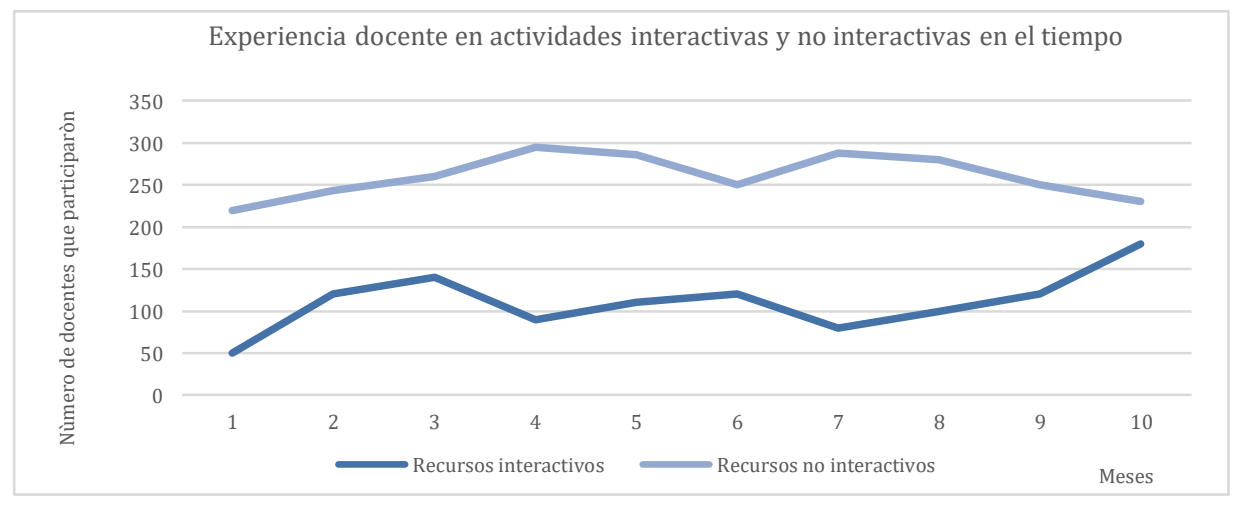


Rodríguez García, Y. M. Reconceptualizacion de la educación en la era digital: educomunicacion, redes de aprendizaje y cerebro. Factores claves en los actuales escenarios de construcción de conocimiento

Gráfico 18: Experiencia docente en actividades interactivas y no interactivas en el tiempo. Elaboración propia

La experiencia docente en este diplomado se diseñó pedagógicamente de acuerdo al perfil cognitivo, por tal motivo conto con un alto contenido de infografías y multimedias interactivas, que estaban enriquecidas con audios, videos y lecturas (Según los resultados de perfil VAK, de docentes), esto exigía que los docentes interactuaran con el material on line. En la gráfica 18, se visualiza la experiencia docente en actividades interactivas y no interactivas en el tiempo, y como se observa hay una evolución en la participación y uso de estos recursos en el tiempo, en general más docentes participan con recursos no interactivos, sin embargo a partir del 7 mes se evidencia un incremento que se mantiene positivo hasta el 10 mes de la experiencia, demostrando que si podemos transformar las practicas docentes a través de la propia interacción de ellos, con estos materiales, incluso si se observa en la gráfica el uso de recursos no interactivos inicio su descenso desde el 7 mes. Al corroborar con el análisis de entrevistas los docentes declaran iniciar sus actividades en el entorno no interactivo en el que se sienten más cómodos, pero reportan en el tiempo sentir curiosidad por indagar lo desconocido de un recurso interactivo.

En este punto es importante considerar los conceptos Vygotskianos, de zona de confort, desarrollo próximo y pánico, en los procesos sociales del aprendizaje. Este concepto se ejemplifica como la distancia entre el nivel de desarrollo efectivo del alumno (lo que puede hacer solo) y el nivel de desarrollo potencial (lo que puede hacer con ayuda de otro). Estos procesos de construcción de conocimiento afloran en la interacción con el grupo, incluso el aumento de la participación en recursos interactivos, también puede obedecer a la llamada inteligencia colectiva, en la que ya no es el individuo de forma independiente el que moldea sus actitudes, sino el grupo.

Estas conductas desde el punto de vista de la neurociencia cognitiva son esperables, el permanecer en la zona de confort, cómo mecanismo de defensa, para luego y gracias a la influencia de compañeros del curso abrir sus actividades, es decir entrar en la zona de aprendizaje próximo, como vislumbro Vigotski desde 1931; es claro que las zonas de confort y de aprendizaje próximo, son muy diferentes para estudiantes y docentes, y lo que puede ser confort para estudiantes es de desarrollo próximo o de pánico para un docente.

En resumen los cambios culturales que trae la era global de la información o era digital repercuten indudablemente en el concepto de educación que tienen los estudiantes y docentes, las expectativas, esperanzas y temores que genera la educación en una sociedad en red, empoderada de los medios, crítica e informada (Osuna, 2007). Mucho del éxito o fracaso en un sistema educativo se puede atribuir a las expectativas previas de estudiantes y docentes, a la aceptación de los retos relacionados con enfrentar situaciones nuevas, con gestionar adecuadamente la información, con aprender a trabajar colaborativamente y empoderar la comunicación al servicio de la educación (Aparici, 2010). 


\subsection{Post concepto de estudiantes y docentes}

Finalmente tras las dos experiencias de docentes y estudiantes, se analizó la evolución del cambio de preconceptos tras la experiencia en educación en entornos digitales, en el Gráfico 19, se presenta un análisis en el que se triangulo la información (entrevistas y encuestas), de conceptos previos, en la experiencia y al final de los cursos.

Evolución del cambio de preconceptos tras la experiencia en educación en entornos digitales

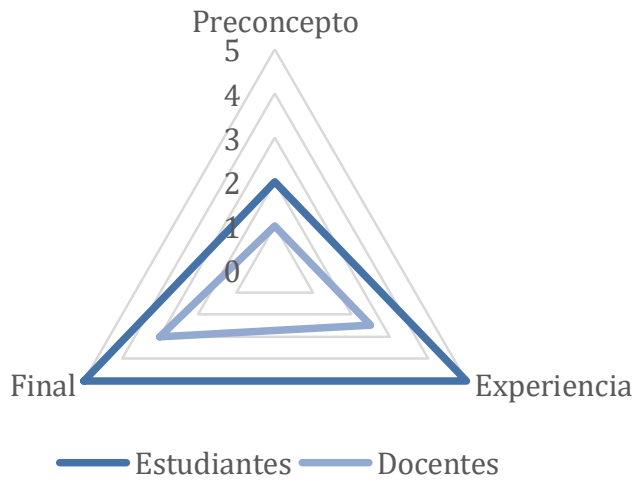

Gráfico 19: Evolución del cambio de preconceptos tras la experiencia en educación en entornos digitales. Elaboración propia

El concepto de estudiantes y docentes cambio en el proceso (gráfico 19), los estudiantes, línea más oscura iniciaron con un preconcepto poco favorable (2), y en la experiencia y finalización del curso hay un aumento en la valoración de la educación en entornos digitales y sube al máximo permitido que es 5 . En caso de los docentes línea más clara, inician con un preconcepto muy poco favorable (1) y en la experiencia aumenta a medianamente favorable $(2,5)$ y al final de la experiencia aumenta (3), la aceptación y favorabilidad frente a los escenarios educativos digitales. Puede notarse un cerebro que se adapta más rápido (mayor plasticidad cerebral), de los estudiantes, respecto a la pausad tasa de cambio de los docentes, una situación apenas natural, teniendo en cuenta el perfil inicial comparativo de los docentes que participaron.

Uno de los pilares para la transición a situaciones nuevas y formación de nuevos conocimientos es el lenguaje, que para el caso de los docentes en este estudio, se constituye en un problema para acceso a la información y la construcción del conocimiento. Esto se relaciona con el discurso de Chomsky, en el año 1988 que aporta importantes análisis sobre el lenguaje, los lenguajes nuevos y los problemas del conocimiento, que emanan en los nuevos entornos (Chomsky, 1988). 
La convergencia de medios y de información permite cambios en la transmisión de la información y creación del conocimiento, en aspectos como: aumento al acceso a la información, su velocidad de procesamiento y distribución, es posible la segmentación de audiencias, emergen otros códigos de lenguaje para comunicarse, nuevas formas de conocer y pensar; dado que estas transformaciones son tan veloces, la reconceptualización epistemológica de la educación debería ser objeto prioritario para los docentes. Gutiérrez Martín, A. (2010).

El cambio conceptual es un proceso gradual, que exige apropiación, experiencia, repetición, tiempo, solo así la memoria puede modificarse a largo plazo (Kandel, E. 2006). El tiempo que se requiere para re conceptualizar desde el punto de vista neurobiológico es el mismo que se gasta el cerebro en reconstruir tejidos y redes neuronales y construir nuevas redes, este proceso biológico implica la división de neuronas o la readaptación de las existentes para cumplir otras funciones, como es biológico está regulado genética y ambientalmente, por lo que los cambios conceptuales y de conducta humana son tan singulares de unos a otros.

Por otro lado los procesos de construcción de nuevos conceptos están influenciados por el tipo de inteligencia predominante del individuo, (Gardner, H.1999). Las llamadas inteligencias múltiples están vigentes, aunque con una mayor comprensión desde la neurociencia, en cuanto a que no hay restricciones para que el cerebro cambie o desarrolle varios tipos de inteligencias. En resumen el cerebro está cambiando siempre, acomodándose a las demandas del entorno, una variable que influye drásticamente para que se activen estos procesos de cambio (plasticidad cerebral), es la motivación.

La pregunta obligada antes de comenzar cualquier proceso de formación (plasticidad y cambio cerebral), seria: ¿Qué nos motiva? y ¿Qué motiva a mis alumnos?

\subsection{Influencia del preconcepto de la educación en entornos digitales sobre el desempeño académico}

Una vez se evaluó la evolución del concepto se estudió si existía alguna influencia del preconcepto de la educación en entornos digitales y el desempeño académico en escenarios educomunicativos, de redes sociales y trabajo colaborativo en estudiantes y docentes. En la gráfica 20, se observan los resultados. 
Rodríguez García, Y. M. Reconceptualizacion de la educación en la era digital: educomunicacion, redes de aprendizaje y cerebro. Factores claves en los actuales escenarios de construcción de conocimiento

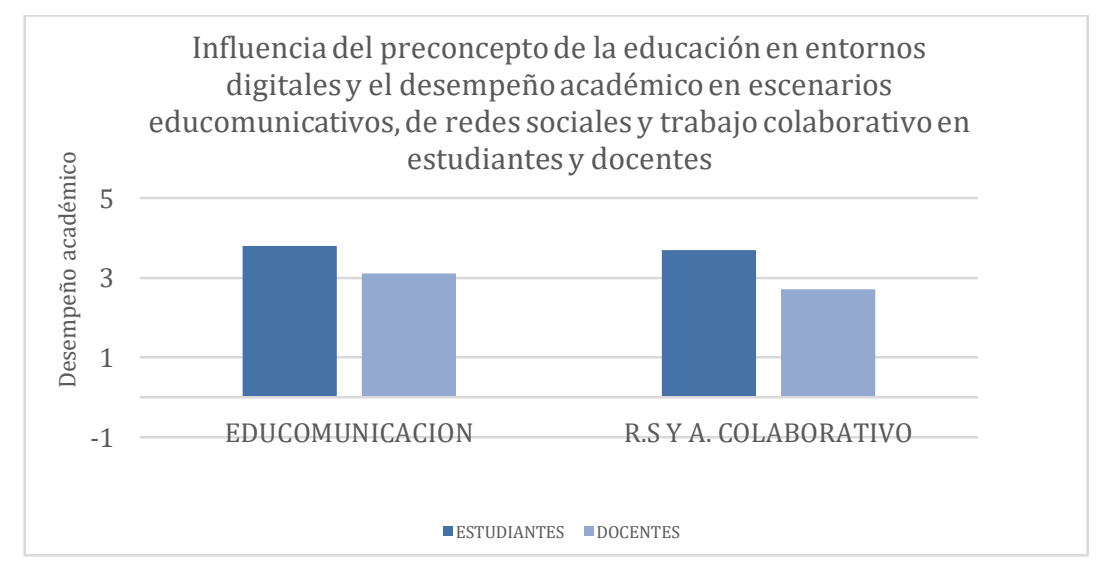

Gráfico 20: Influencia del preconcepto de la educación en entornos digitales y el desempeño académico en escenarios educomunicativos, de redes sociales y trabajo colaborativo en estudiantes y docentes. Elaboración propia

Como se describió en la gráfica 19 , el preconcepto de los docentes sobre la educación en entornos digitales era de 1 (muy poco favorable) y el de los estudiantes de 2 (poco favorable). En el Gráfico 20, se evidencia que: los estudiantes que tenían de base un mejor preconcepto tuvieron un mejor desempeño académico en todas las actividades de la experiencia en el curso, lo contrario ocurrió con los docentes.

En conclusión el preconcepto base impacta directamente en el desempeño académico y conducta en actividades, por ejemplo la orientación al logro o el trabajar en la motivación intrínseca. La reconceptualización de la educación en la era digital permite dimensionar los grandes retos que asumen en general las universidades y que están enmarcados en el acelerado desarrollo informacional, que tiene incidencias en lo social, lo técnico y lo económico y tiene repercusiones directas en la educación en la llamada informática educativa, que le da un significado práctico a los medios informáticos y los aplica al contexto concreto educacional (Castells M. y Himanen P. 2016). El desarrollo informacional se constituyó a escala global a comienzos del siglo XXI (Castells 2000 y 2004; Cohen 2005). La característica del informacionalismo es el uso de información digital y de tecnologías de la información y comunicación, lo que incrementa la difusión de organizaciones en red en los ámbitos de la vida social y económica; así como también se potencia el procesamiento de la información y de la comunicación digital, posibilitando el crecimiento de la llamada sociedad de la información. Las tecnologías de la información permiten que el conocimiento y la información se distribuyan y apliquen en cualquier contexto, por lo que el aumento de la productividad desde la década de los 90, se ha denominado "la nueva economía" (Castells 2001), aspecto que debe ocupar un lugar preponderante en las universidades que convienen centrar sus esfuerzos para educar a jóvenes en las competencias que requieren esta sociedad y cultura que se transforma permanentemente.

\subsection{Relación entre motivación y escenarios de aprendizaje educomunicativos}


Rodríguez García, Y. M. Reconceptualizacion de la educación en la era digital: educomunicacion, redes de aprendizaje y cerebro. Factores claves en los actuales escenarios de construcción de conocimiento

Finalmente se estableció la relación entre motivación (extrínseca e intrínseca) de estudiantes y docentes con mejor desempeño y escenarios de aprendizaje educomunicativos, los resultados se visualizan en el Gráfico 21.

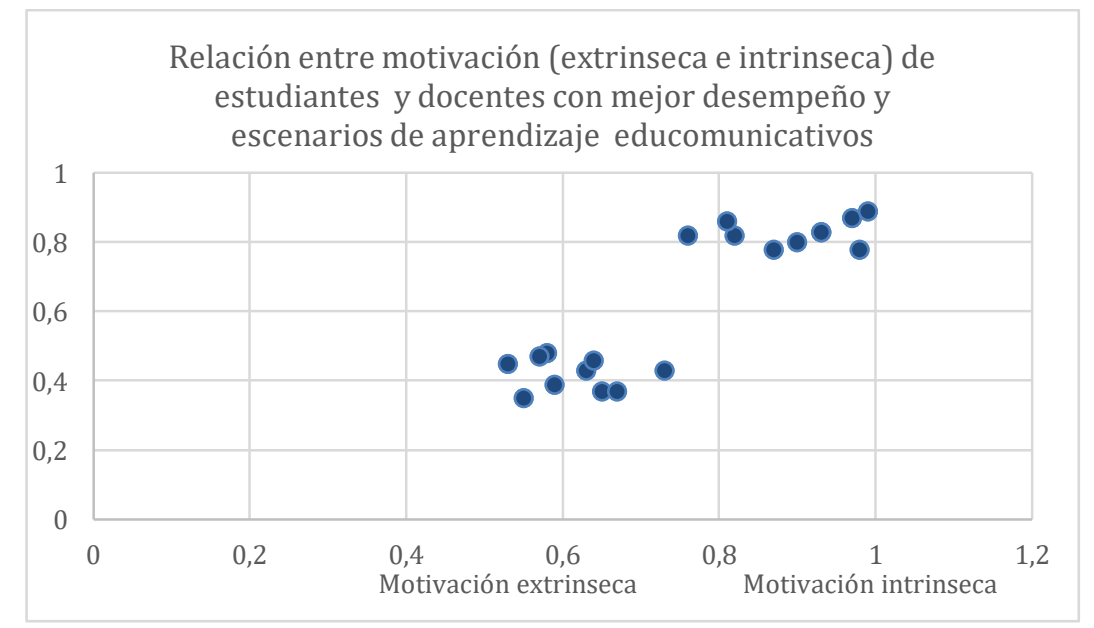

Gráfico 21: Relación entre motivación (extrinseca e intrinseca) de estudiantes y docentes con mejor desempeño y escenarios de aprendizaje educomunicativos. Elaboración propia

Para construir esta relación entre motivación y desempeño, primero se estableció el perfil motivacional de estudiantes y docentes, basándonos en la escala de jerarquía de necesidades humanas aplicadas (fisiológicas, seguridad, afiliación, reconocimiento y autorrealización), (Maslow, 2005); se construyó un cuestionario para valorar la motivación y de qué tipo predominantemente (intrínseca-extrínseca), en una escala de 0 a 1.0; en el que se puntuaron aspectos intrínsecos (recompensa social, autorrealización, reconocimiento y afiliación) y extrínsecos (el logro, la ponderación evaluativa, la posibilidad de seguir en el sistema educativo), que tienen que ver con la motivación. Participaron 100 docentes y 100 estudiantes que habían obtenido los mejores desempeños en las actividades de corte educomunicativo.

En el Gráfico 21 se observa un gráfico de dispersión que comparara dos conjuntos de pares de datos (estudiantes Vs docentes) y permite ver la relación entre conjuntos de valores; los puntos cercanos al valor 0,6 corresponden a relaciones de variables de motivación extrínseca y los puntos superiores a partir de 0,8 , corresponden a las relaciones de variables de motivación intrínseca.

Como es evidente, los estudiantes y docentes con mejor desempeño en las actividades de corte educomunicativo están motivados por variables intrínsecas, cómo la afiliación y autorrealización (cercana a 1), la recompensa social y el reconocimiento. Es decir que posibilitar el dialogo y la crítica si redunda en activación de sistemas motivacionales de alto nivel como la realización humana.

La invitación de Piaget, de ponerle más cerebro a la gestión pedagógica y diseño curricular, en su libro la adaptación vital y la psicología de la inteligencia, sigue 
Rodríguez García, Y. M. Reconceptualizacion de la educación en la era digital: educomunicacion, redes de aprendizaje y cerebro. Factores claves en los actuales escenarios de construcción de conocimiento

vigente, así como la de Freinet, de empoderar a los estudiantes en su proceso (Piaget, J. 1976).

Aporta a lo anterior los hallazgos en neurociencia cognitiva, es decir los procesos neurobiológicos, psicológicos y ambientales que subyacen a los procesos de atención, conciencia, lenguaje, aprendizaje, memoria, toma de decisiones, coconstrucción, autotrascendencia, creatividad y sus manifestaciones en la conducta, se han venido articulando cada día más a los procesos académicos aplicados, incluso surgen áreas nuevas de investigación como la neuropedagogía, que integra la psicología, la pedagogía y las neurociencias y las proyecta para el mejoramiento de la práctica educativa. Conocer cómo razonamos, el estilo cognitivo, los intereses de cada población, pueden aportar en ofrecer una educación significativa, en contexto que realmente transforme actitudes y comportamientos en un entorno determinado (Damasio, A. 2010).

\section{CONCLUSIONES}

Los preconceptos sobre la educación en entornos digitales, influyeron directamente en la motivación, los procesos de comunicación y el desempeño académico, en la muestra estudiantes y docentes expuestos a su primera experiencia en educación virtual.

El concepto sobre educación en entornos digitales, se puede modificar tras la experiencia. Se evidencio un cambio más rápido en el tiempo, en los conceptos de los estudiantes, respecto a los de los docentes, quienes cambian sus conceptos con una tasa más lenta respecto a los jóvenes, pero de forma profunda, esto puede atribuirse a las diferencias en los estilos cognitivos, conductuales y generacionales.

La relación entre actividades educomunicativas y aumento de la motivación intrínseca, fue clara en ambas muestras (estudiantes y docentes). Lo que invita a que se siga trabajando en el fortalecimiento de esta filosofía y práctica educativa, que parece ser la que mejor le calza a la educación en la era digital.

El análisis del desempeño en los estudiantes, evidencia que: tuvieron mejores aprendizajes en actividades lúdicas, de radio, de la web 2.0 y redes sociales, pero que deben mejora en actividades de trabajo colaborativo y que impliquen programación. Por su parte el análisis del desempeño en los docentes, evidencia que: presentan preferencia por las actividades sincrónicas y/o presenciales, el trabajo colaborativo y radiales, pero que deben mejorar el desempeño en el uso de herramientas de la web2.0, actividades que impliquen programación, los juegos y participación en actividades en redes sociales.

Por mejorar: Como se nota, este estudio evaluó dos poblaciones diferentes no solo por su rol, en la academia, sino por razones generacionales, se plantea hacer estudios comparativos entre poblaciones un poco más similares y corroborar los resultados. Sin embargo, este es el disparejo panorama universitario, que requiere una intervención en mi concepto desde la base de lo que a cada parte motiva, y una 
Rodríguez García, Y. M. Reconceptualizacion de la educación en la era digital: educomunicacion, redes de aprendizaje y cerebro. Factores claves en los actuales escenarios de construcción de conocimiento

continua evaluación de las ideas previas y conceptos en ocasiones arraigados, al pasado que pueden anquilosar el cambio necesario.

Prospectiva: Las mejoras en el sistema académico, la pedagogía y la didáctica, parten no solo de los recursos físicos, políticos, de espacios y tecnologías, deben también partir de una concepción vigente de los docentes y estudiantes frente a las necesidades culturales, de desarrollo y acorde a los objetivos de Desarrollo Sostenible, esto implica una necesidad de intervenir en el fortalecimiento docente. Delors, en su escrito "El personal docente en busca de nuevas perspectivas", plantea ya desde el siglo pasado la realidad que cada vez es más cambiante en la práctica pedagógica (Delors, J. 1996).

Finalmente, en palabras de la Dra Sonia Ma. Santoveña Casal, en aparte del artículo de análisis de cursos virtuales, del 2007: "Conocer qué aspectos de nuestros cursos virtuales requieren ser modificados y actualizados puede ayudarnos a desarrollar y publicar nuevos recursos telemáticos. Evitando posturas defensivas y actuando sobre la base de la mejora continua" (Santoveña,S. 2007. Pag 88) Nada es estático, menos el conocimiento de nuestro magnifico sistema cognitivo $y$, por ende de la pedagogía. Paradójicamente los docentes somos la población más difícil de educar, o de intervenir, ¿Por qué tanta reticencia al cambio? si trabajamos con lo que más cambia: nuestro cerebro.

\section{REFERENCIAS}

Aparici R. (2010). Conectados en el ciberespacio. Madrid: UNED.

Aparici, R. (2010): Educomunicación: Más allá del 2.0. Madrid: Gedisa

Barbas Ángel, C. (2012). Educomunicación: Desarrollo, enfoques y desafíos en un mundo interconectado. Foro de Educación, 14, 157-175.

Baron-Cohen, S. (2003), The essential difference. London: Penguin Books [Trad. esp. LaGran diferencia: cómo son realmente los cerebros de hombres y mujeres. Barcelona Amat Editorial, 2005].

Blaikie, N. W. H. (1996): A critique of the use of triangulation in social research, Quality and Quantity, n 25, 115-136

Camarero-Cano (2015) Comunidades tecnosociales. Evolución de la comunicación analógica hacia la interacción analógico-digital. Revista Mediterránea de Comunicación, 6(1), 187-195

Castells, M (2001 y 2004). The Informatión Age: Economy, Society and Culture. 2a. ed, vol 1: The rise of the Network Society, Oxford: Blackwell (2000). Vol. 2: The power of Identity, Oxford: Blackwell, 2004. Vol 3 End of Millennium, Oxford: Blackwell, 2000. 
Rodríguez García, Y. M. Reconceptualizacion de la educación en la era digital: educomunicacion, redes de aprendizaje y cerebro. Factores claves en los actuales escenarios de construcción de conocimiento

Castells M. y Himanen P. (2016). Reconceptualización del desarrollo en la era global de la información. Fondo de Cultura Económica.

Castells, M. (2000). La era de la información. Madrid: Alianza.

Chomsky, N., (1988). Language and problems of knowledge. Cambridge: The MIT Press [Trad. Esp. El lenguaje y los problemas del conocimiento. Madrid: Visor, 1992].

Damasio, A. (2010). Y el cerebro creó al hombre. Barcelona: Ediciones Destino.

Delors, J. (1996). La educación encierra un tesoro. Madrid: Santillana.

Diego Redolar Ripoll (2014). Neurociencia Cognitiva. Editorial Médica Panamericana

Gardner, H. (1999). Intelligence reframed: multiple intelligences for the $21^{\text {st }}$ Century, York: Basic Book [Trad. esp. La inteligencia reformulada. Barcelona: Paidos, 2001].

Glaser, Barney G.; Strauss, Anselm L. (1967). The discovery of grounded theory: strategies for qualitative research. New York: Aldine de Gruyter

Gutiérrez Martín, A. (2010). Creación multimedia y alfabetización en la era digital. En R. Aparici, (Coord.) Educación: más allá del 2.0 (pp. 171-186). Barcelona: Gedisa.

Kandel, E. (2006). In search of memory, New York: Norton [Trad. esp. En busca de laMemoria. Buenos Aires: Katz Editores, 2007].

Kaplún, M. (2010). Una pedagogía de la comunicación. En R. Aparici, (Coord.) Educomunicación: más allá del 2.0. (pp.41-64). Barcelona: Gedisa Comunicación educativa.

Lévy, Pierre. (2004). Inteligencia Colectiva por una antropología del ciberespacio. Washington: Organización Panamericana de la Salud (Unidad de Promoción y Desarrollo de la Investigación y el Centro Latinoamericano y del Caribe de Información en Ciencias de la Salud.

Lopez Aloso, C. y Matesanz del Barrio, M. (Eds) (2009). Las plataformas de aprendizaje. Del mito a la realidad. Madrid: Biblioteca Nueva.

Lazo, M.; Gabelas Barroso, J. A. (2016). Comunicación Digital - Un modelo basado en el factor R-elacional. España: Editorial OUC.

Maslow Abraham J (2005). El management una visión humanista para la empresa de hoy (orig.: Maslow on Management). Barcelona: Editorial Paidós Ibérica. 
Rodríguez García, Y. M. Reconceptualizacion de la educación en la era digital: educomunicacion, redes de aprendizaje y cerebro. Factores claves en los actuales escenarios de construcción de conocimiento

Osuna, S. y Busón, C. (2007). Convergencia de Medios. La Integración Tecnológica en la Era Digital. Barcelona: Icaria.

Piaget, J. (1976). Adaptation vitale et psychologie de /'intelligence. Paris: Hermann.

Santoveña Casal, S. M. ${ }^{a}$ (2007) Análisis de cursos de Educación Social en entornos virtuales de aprendizaje y su influencia en la calidad. Enseñanza, 25, 77-90.

Strauss, Anselm, Corbin, Juliet. (1994). Grounded theory methodology, an overview. In: Yvonne, S, Lincoln. Denzin, Norman k. Handbook of qualitative research. (pp. 273-285). London. Sage Publications

\section{Web grafía:}

Ministerio de Tecnologías de la Información y las Comunicaciones (3 de Agosto 2016) 8 de cada 10 colombianos están usando Internet. Recuperado en: http://www.mintic.gov.co/portal/604/w3-article-1629.html

Ministerio de Educación Nacional de Colombia. (10 de Junio de 2010). Sistema de aseguramiento de la calidad de la educación superior. En: http://www.mineducacion.gov.co/1759/w3-article-235585.html

Ministerio de Educación Nacional de Colombia. (8 Abril del 2014). Lineamientos de política de educación superior inclusiva. Recuperado de: http://www.mineducacion.gov.co/1759/w3-article-340146.html

Sistema Nacional de Información de la Educación superior SNIES (s.f). Recuperado 1 de Diciembre de 2016 de: http://snies.mineducacion.gov.co/consultasnies/programa\#

Siemens, G (2010). Conociendo el conocimiento (Grupo Nodos Ele, trad.) Recuperado

http://craig.com.ar/biblioteca/Conociendo\%20el\%20Conocimiento\%20\%20George\%20Siemens.pdf (Obra original publicada en 2006)

UNESCO. La UNESCO y los Objetivos de Desarrollo Sostenible (s.f) Recuperado de 12 Diciembre de 2016 en: http://es.unesco.org/sdgs

Universidad Manuela Beltrán Virtual (2016), Quienes somos: Modelo Pedagógico UMB Virtual. Recuperado de: http://umbvirtual.edu.co/quienes-somos/ 
Rodríguez García, Y. M. Reconceptualizacion de la educación en la era digital: educomunicacion, redes de aprendizaje y cerebro. Factores claves en los actuales escenarios de construcción de conocimiento

\section{AUTOR}

\section{Yeldy Milena Rodríguez García}

Docente, Investigadora, Gestora académica.

Bióloga y Magister en Neurobiología de la Pontificia Universidad Javeriana de Bogotá Magister en Redes Sociales y aprendizaje Digital y Doctoranda en Comunicación y Educación en Entornos Digitales de la Universidad Nacional de Educación a Distancia de España UNED 